WALDEN

UNIVERSITY

A higher degree. A higher purpose.

Walden University

ScholarWorks

Walden Dissertations and Doctoral Studies

Walden Dissertations and Doctoral Studies

Collection

2015

\title{
Increasing Initiation and Exclusivity of Breastfeeding in the Hospitalized Postpartum Dyad
}

Candace L. Rouse

Walden University

Follow this and additional works at: https://scholarworks.waldenu.edu/dissertations

Part of the Nursing Commons, and the Obstetrics and Gynecology Commons

This Dissertation is brought to you for free and open access by the Walden Dissertations and Doctoral Studies Collection at ScholarWorks. It has been accepted for inclusion in Walden Dissertations and Doctoral Studies by an authorized administrator of ScholarWorks. For more information, please contact ScholarWorks@waldenu.edu. 


\title{
Walden University
}

\author{
College of Health Sciences
}

This is to certify that the doctoral study by

\author{
Candace Rouse
}

has been found to be complete and satisfactory in all respects, and that any and all revisions required by the review committee have been made.

Review Committee

Dr. Eric Anderson, Committee Chairperson, Health Services Faculty

Dr. Janice Belcher, Committee Member, Health Services Faculty

Dr. Patti Urso, University Reviewer, Health Services Faculty

Chief Academic Officer

Eric Riedel, Ph.D.

Walden University

2015 


\author{
Abstract \\ Increasing Initiation and Exclusivity of Breastfeeding \\ In the Hospitalized Postpartum Dyad \\ by \\ Candace L Rouse \\ MSN, University of Phoenix 2000 \\ BSN, Florida Southern College 1998 \\ Project Study Submitted in Partial Fulfillment \\ for the Requirements for the Degree of \\ Doctor of Nursing Practice
}

Walden University

May 2015 


\begin{abstract}
The purpose of this project was to highlight an intervention to increase breastfeeding initiation and exclusive breastfeeding during the birth hospitalization in a coastal mid-Atlantic inner city hospital. Although researchers and national standards promote early initiation and exclusive breastfeeding, there continues to be a significant number of women who do not breastfeed and/or supplement with formula. The advantages of breastfeeding for mother and infant are substantial and include protecting babies from allergens to reducing maternal breast and ovarian cancer. Breastfeeding rates of initiation and exclusivity at the project hospital were below benchmarks set by international, national, and state agencies. The project intervention utilized bedside RNs who were educated and trained by the Perinatal Unit Clinical Nurse Specialist and the unit lactation counselors on bedside lactation support. The educational intervention capitalized on Dennis's theory of breast-feeding self-efficacy, which emphasizes maternal confidence in breastfeeding success. A convenience sample of breastfeeding rates of initiation and exclusivity from one month's delivered mothers pre-intervention $(n=203)$ compared to one month's breastfeeding rates of delivered mothers post-intervention $(n=220)$ was derived from electronic medical record nursing documentation and formed the data points for analysis. Outcome measures demonstrated an institutional increase in rates of breastfeeding initiation and in breastfeeding exclusivity. Chi-square analysis of both outcomes was not statistically significant; however progression towards the benchmarks was made, demonstrating clinical significance. Future social change from the project's success will be evident in reduction of sequelae from the above named maternal and infant acute and chronic illnesses.
\end{abstract}


Increasing Initiation and Exclusivity of Breastfeeding In the Hospitalized Postpartum Dyad

by

Candace L. Rouse

MSN, University of Phoenix 2000

BSN, Florida Southern College 1998

Project Study Submitted in Partial Fulfillment

for the Requirements for the Degree of

Doctor of Nursing Practice

Walden University

May 2015 


\section{Table of Contents}

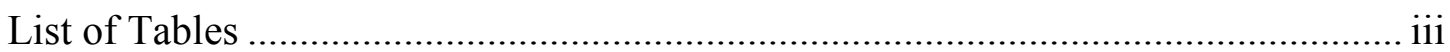

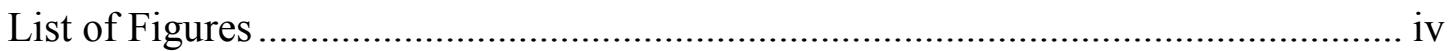

Section 1: Overview of the Evidence Based Project ...............................................

Increasing Initiation and Exclusivity of Breastfeeding................................. 1

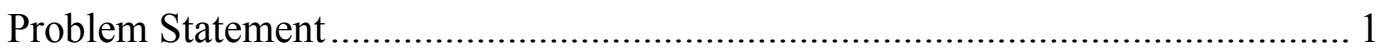

Purpose Statement and Project Objectives ....................................................... 3

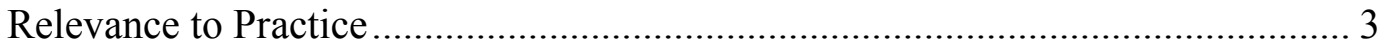

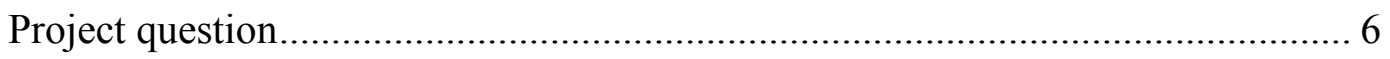

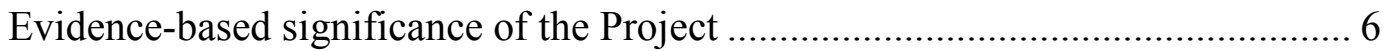

Implications for social change in practice ............................................. 7

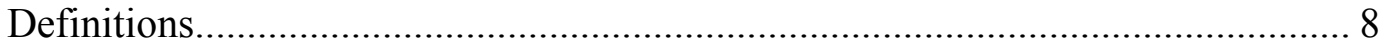

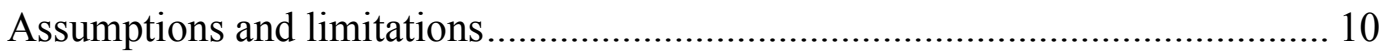

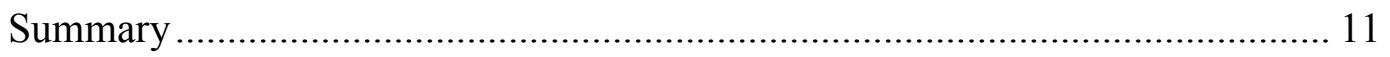

Section Two: Review of Scholarly Evidence .................................................. 11

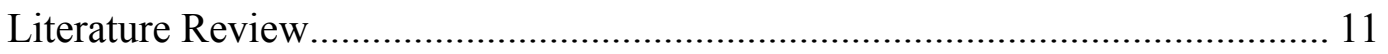

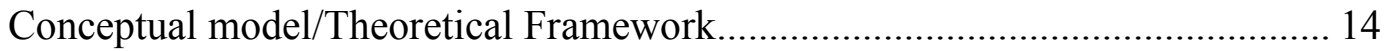

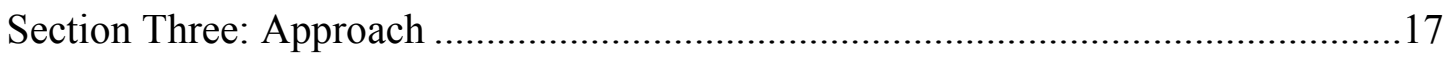

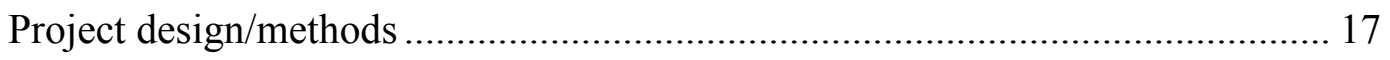

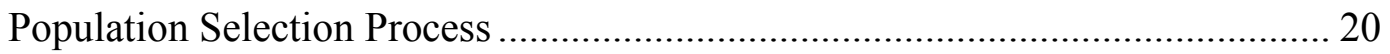

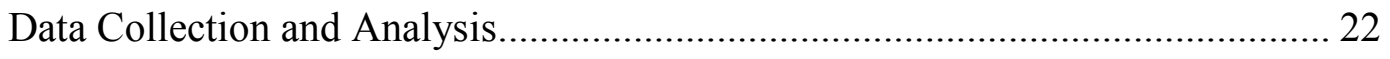


Protection of Human Subjects.

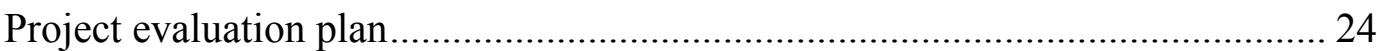

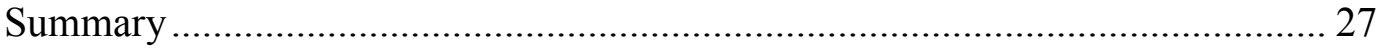

Section Four: Discussion and Implications...............................27

Summary of Findings....................................27

Discussion of Findings.................................... 31

Implications............................................. 32

Strengths and Limitations...................................33

Analysis of Self.............................................

Summary and Conclusions................................35

Section Five: Scholarly Project......................................36

APPENDIX A: Maryland Breastfeeding Recommendations ........................... 44

APPENDIX B: Objectives for RN Educational Intervention ............................ 1

APPENDIX C: RN Breastfeeding (Educational Intervention) Competency.......... 2

APPENDIX D: RN Documentation of Breastfeeding Interventions .................... 3

APPENDIX E: The Essentials of Doctoral Education ......................................... 5

APPENDIX F: Presentation to Women \& Children's Leadership ....................... 5

APPENDIX G: Evidence Based Practice Poster Abstract Submission ............... 58 


\section{List of Tables}

Table 1. Objectives with Measureable Outcomes ........................................................

Table 2. Healthy People 2020 Process Indicators.....................................................

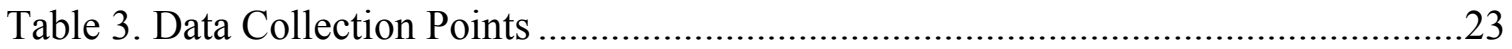

Table 4. Electronic Medical Record (EMR) Breastfeeding Data Collection...............23

Table 5. Descriptive Demographic Statistics........................................29

Table 6.Post Intervention Joint Commission Data Analysis..............................30 


\section{List of Figures}

Figure 1. Measurement and Monitoring Data ...............................................................18

Figure 2. Run chart for Joint Commission Breastfeeding Outcomes ................................24

Figure 3. Post Intervention Initiation of Breastfeeding in First Hour Outcomes...........30

Figure 4. Post Intervention Exclusive Breastfeeding on Discharge Outcomes............31 
Section 1: Overview of the Evidence Based Project

Increasing Initiation and Exclusivity of Breastfeeding

Quality outcomes from exclusive breastfeeding for mother and infants have been investigated nationally and internationally (Centers for Disease Control [CDC], 2011; World Health Organization, 2011). Numerous projects are ongoing in institutions to encourage women to breastfeed and consequently discourage formula supplementation (Baby-Friendly USA, 2013). Components of an intervention to encourage increased initiation and exclusivity of breastfeeding in the immediate postpartum period for the maternal infant dyad are described in the following paper.

\section{Problem Statement}

Breastfeeding has been recognized in literature and by national organizations as the sustenance of choice for newborns up to the age of 6 months (McQueen, Dennis, Stremler, \& Norman, 2011) Infants who breast feed have fewer allergies, fewer upper respiratory infections, and a lower risk of Sudden Infant Death Syndrome (SIDS)(American Academy of Pediatricians, 2011). Breastfeeding has maternal psychological benefits as well as economic and environmental benefits for the parents since there is no need to purchase formula or to dispose of formula bottles (U.S. Department of Health and Human Services, 2011).The American Academy of Pediatricians and the World Health Organization, as well as the U.S. Healthy People initiative, have recommended that mothers exclusively breastfeed their infants for the first 6 months of life. Despite literature and national standards, there continues to be an abundance of new mothers who either choose formula feeding or discontinue breastfeeding at an early age (Li et al, 2003 as cited in McQueen et al., 2011). 
The most current breast feeding data demonstrated a national rate of $75 \%$ initiation of breastfeeding, a 59\% rate of breastfeeding at 3 months, and a 23\% rate of breastfeeding at 12 months (CDC, 2011). The Healthy People 2020 initiatives, a set of goals for disease prevention and health promotion from the United States Department of Health and Human Service, were released in December 2010. These initiatives set 2020 targets for breastfeeding initiation at 81.9 $\%$ and exclusive breastfeeding at discharge to $85.8 \%$. Exclusive breastfeeding was addressed by the goal "to reduce the proportion of breastfed newborns who receive formula supplementation within the first 2 days of life" (CDC, 2011).

The breastfeeding rates among socially disadvantaged women are noted to be lower than the national average (McQueen, Dennis, Stremler \& Williams, 2011). Black women breastfeed at a lower rate than White women (McCarter-Spaulding \& Gore, 2009, as cited by Eidmann, 2011). This was significant for this project due to the depressed economy and diversity of the population surrounding the institution where this project was implemented (Sinai Hospital, 2013).

Maternal confidence in breastfeeding (defined in those studies as self-efficacy) is a significant variable in breastfeeding success (Dykes \& Williams, 1999; O’Campo, Faden, Gielen, \& Want, 1992, as cited by Wheeler \& Dennis, 2013). Measurement of breastfeeding selfefficacy was done in these studies by utilizing the Dennis Breastfeeding Self Efficacy Scale (Dennis, 1999). The 33 item 5 point Likert scale was administered pre-delivery and prior to discharge. The item statements are preceded by the phrase "I can always" with $1=$ not at all confident and 5 = very confident. The overall score ranged from 33-165, with the higher scores indicating higher identification of women's levels of self-efficacy. The survey scores assisted nurses to use targeted interventions designed to increase maternal self-efficacy related to 
breastfeeding. This in turn resulted in increased breastfeeding success and duration (Pollard \& Guill, 2009). Utilizing these interventions to increase maternal breast feeding self-efficacy was effective in raising the hospital breastfeeding rates.

The identified problem for this project was that a need existed for interventions to increase the initiation and exclusivity of breast feeding for immediate postpartum hospitalized women in a coastal mid-Atlantic inner city hospital.

\section{Purpose Statement and Project Objectives}

The purpose of this study was to increase initiation and exclusivity of breastfeeding in the hospitalized postpartum woman via an educational module to staff RNs. This module consisted of interventions to increase bedside lactation support and build maternal confidence in breastfeeding success (defined as breastfeeding self-efficacy). The specific program objectives with measurable outcomes are listed in Table 1.

Table 1

Objectives with Measureable Outcomes

\begin{tabular}{ll}
\hline \multicolumn{1}{c}{ OBJECTIVE } & \multicolumn{1}{c}{ MEASUREABLE OUTCOME } \\
\hline $\begin{array}{l}\text { Demonstrate increased } \\
\text { initiation of } \\
\text { breastfeeding }\end{array}$ & $\begin{array}{l}\text { Number and percent of mother's who were able to } \\
\text { initiate breastfeeding with one hour of birth (CDC, 2010) }\end{array}$ \\
$\begin{array}{l}\text { immediately after birth } \\
\text { Demonstrate an increase } \\
\text { in exclusive }\end{array}$ & $\begin{array}{l}\text { Number and percent of non-NICU term babies } \\
\text { exclusively breastfed during hospital stay (Perinatal Core } \\
\text { breastfeeding during the } \\
\text { newborn's entire } \\
\text { hospital stay }\end{array}$ \\
\hline
\end{tabular}

\section{Relevance to Practice}

Infants who breast feed have fewer allergies, fewer upper respiratory infections, and a lower risk of Sudden Infant Death Syndrome (American Academy of Pediatrics, 2011). 
Breastfeeding contributes to the health and well-being of mothers as it has been shown to reduce the risk of ovarian and breast cancer (World Health Organization, 2013). Breastfed infants are less likely to be obese in adolescence and adulthood. They are also less vulnerable to developing both Type 1 and Type 2 diabetes (American Academy of Pediatrics, 2011).

Initiation of breastfeeding within 1 hour after delivery and exclusive breastfeeding while hospitalized are two components of the Joint Commission's Perinatal Core Measures (United States Breastfeeding Committee, 2010). Reporting of these core measures became mandatory January 1,2014 , and is specifically measuring the number of exclusively breast milk-fed term infants as a percentage of all term infants.

Healthy People 2020 objectives are to improve the health of the mother/infant dyad. One way to do this is to increase breastfeeding (CDC, 2010). Data are reported as noted in Table 2. Table 2

Healthy People 2020 Process Indicators

\begin{tabular}{lll}
\hline Indicator & Time Frame & Target \\
\hline $\begin{array}{l}\text { Increase the proportion of infants } \\
\text { who are breastfed }\end{array}$ & Ever & $81.9 \%$ \\
$\begin{array}{l}\text { Reduce the proportion of } \\
\text { breastfed newborns who receive } \\
\text { formula supplementation in the }\end{array}$ & $\begin{array}{l}\text { First 2 days of } \\
\text { first 2 days of life } \\
\text { (correlates with the Joint }\end{array}$ & $14.2 \%$ \\
$\begin{array}{l}\text { Commission Core Measure 5: } \\
\begin{array}{l}\text { Exclusive breastfeeding at } \\
\text { discharge) }\end{array}\end{array}$ & $\begin{array}{l}\text { Discharge from } \\
\text { hospital }\end{array}$ & $85.8 \%$ \\
\hline
\end{tabular}

These data are available by state, as well as by national statistics, and can be accessed on the CDC website as a Breastfeeding Report card:

(http://www.cdc.gov/breastfeeding/data/reportcard/reportcard2012.htm). 
The state of Maryland has provided process initiatives to assist staff in aiding mothers and infants towards understanding the beneficial outcomes of exclusive breastfeeding. These are being recommended as guidelines for all hospitals in the state (Maryland Department of Health and Mental Hygiene, 2013 [Appendix A]). Signed statements of support were sent to the Maryland Department of Health and Mental Hygiene (Md. DHMH) from health care organizations' presidents. The project hospital pledged their promotion of breastfeeding by completing and sending to the Md. DHMH the above named signed statement of support.

The two nurse sensitive indictors reported to the National Database of Nursing Quality Indicators (American Nurses Association, 2009) for breastfeeding in the project hospital are (a) Initiation of breastfeeding within one hour after delivery, and (b) Breastfed Supplementation; both expressed in percentages. The Joint Commission core measure is exclusive breast milk feeding during hospitalization while the CDC measure is percent of infants receiving formula before 2 days of age. Although these are expressed in different terms, they are the same data.

Benchmarked data in the institution are from the Healthy People 2020 recommendations, with the desired outcome to bring the current actual data to the targeted benchmark. The targets and the current hospital data are:

- L\&D: breastfeeding initiation within one hour; Target: $81.9 \%$, Actual: $54.29 \%$

- Mother Baby: exclusive breastfeeding at discharge; Target: $85.8 \%$, Actual $63.6 \%$ Sustaining this DNP project enhances the health of the mother/infant dyad. The project was aligned with the hospitals strategic priorities of reducing unnecessary readmissions (for mother and/or infant), produce mandated quality results and improve scores on core measures (Sinai Hospital, 2011). 


\section{Project Question}

Does staff RN education on bedside lactation support increase breastfeeding outcomes for women who desire to breastfeed in the hospitalized postpartum period?

\section{Evidence-Based Significance of the Project}

The problem of inadequate rates of breastfeeding initiation and exclusivity in the organization was identified by practice experts (the institution's Internationally Board Certified Lactation Counselors, [IBCLCs]) and myself as the Clinical Nurse Specialist (CNS). As the CNS, I am responsible for establishing best practices as well as reporting accurate data for benchmarking on institutional and national level. This inquiry marked the recognition of the problem and the need for an evidenced based practice (EBP) solution.

EBP was described by Melnyk, Fineout-Overholt, Stillwell and Williamson (2009) as "a problem solving approach to the delivery of health care". EBP is the combination of best practices from research, clinical expertise and patient preference (Sacket, 2000 as cited in Melnyk et al., 2009). The Rosswurm and Larrabee Model for EBP (1999) is a means to change practice via these components to increase quality healthcare outcomes. With the breastfeeding percentages as the identification of a problem trigger, the EBP practice change began with the assessment of a need for change in the current breastfeeding support and an increase in education for bedside RNs. Rosswurm and Larrabee's model guided this project and is listed below as an outline.

1. Assess the need for change in practice.

2. Link the problem interventions to outcomes.

3. Synthesize best evidence.

4. Design the practice change. 
5. Implement and evaluate the change in practice.

6. Integrate and maintain the change in practice.

Preproject, lactation support was done exclusively by the IBCLCs. Patients were informed that the institution IBCLCs would assist them with individual breastfeeding support. The four IBCLCs consulted on every breastfeeding mother, with the bedside staff documenting the number and duration of feeds. Post-project, the bedside RNs were the initial contact for lactation support, with the IBCLCs functioning as true consultants and educators.

\section{Implications for Social Change in Practice}

Short term implications for not breastfeeding include the initial complications for mother and child after delivery. Oxytocin is released when the infant nurses, which contracts the uterus, reducing the potential for maternal postpartum hemorrhage. Colostrum, which is the precurser to breast milk, consists of antibodies and proteins influential to optimal infant health and development (American Academy of Pediatricians and the American College of Obstetricians and Gynecologists, 2009).

Long term implications for not breastfeeding include the already mentioned effects on infant health (fewer allergies and upper respiratory infections and a lower risk of SIDS). Maternal long term implications have been researched as well. These include a lower risk of some forms of cancer, reduced risk of osteoporosis, as well as a psychological benefit of reduced stress. Reduction of maternal stress is believed to be related to oxytocin and prolactin hormones which are released during breastfeeding (Schanler, 2013).

In addition to physical benefits from breastfeeding, economic benefits have been documented. Weimer (2001), in a meta-analysis noted that increasing exclusive breastfeeding to recommended rates would save $\$ 3.6$ billion. Savings would come from reducing formula costs, 
physician and clinic visits, as well as indirect costs such a parental wages lost when staying home to care for the sick child (Weimer, 2001). Included in this data were incidence rates from published studies to estimate the reduction in the number of cases of otitis media, gastroenteritis, and necrotizing enterocolitis that would be actualized with increased breastfeeding (Weimer, 2001). A more current overview was found that reports that infants who breastfed for three months had fewer physician office visits and hospitalizations. It was reported that a savings of $\$ 331$ per infant care was demonstrated. Exclusive breastfeeding for 6 months was projected to demonstrate a cost savings of 13 billion dollars (Schanler, 2012).

Providing self-efficacy enhancing interventions (confidence building regarding breastfeeding) will not only benefit the individual maternal/infant dyad, but also society by improving economic benefits to society as well contribute to the overall health of mothers and infants. This project demonstrated that using interventions to increase maternal self confidence in breastfeeding (breastfeeding self-efficacy) by the bedside RNs increased the rate of breastfeeding initiation and exclusivity.

\section{Definitions}

Exclusive breastfeeding at discharge from hospital:_Defined and reported as no formula or water supplementation while the newborn is hospitalized (Joint Commission, 2011).

Self-efficacy: An individual's belief that they will accomplish a goal. It is the individual's expectation that a positive outcome will occur as a result of their mastery of a situation or a skill (Bandura, 1977, as cited by Dennis, 1999). Concepts of mastery of past experiences, social modeling by observation of others, social persuasion by encouragement from others and learning how to deal with pain, anxiety and fatigue to effect success are the framework of self-efficacy (Bandura, 1977, as cited by Dennis, 1999). Measurement of self- 
efficacy is done via Likert scaled questions. Questions are answered on a numbered scale with answers such as not at all confident (0) to moderately confident (3) up to totally confident (5). Higher scores reflect higher degrees of self-efficacy.

Breastfeeding self-efficacy: A mother's perception of her ability or confidence to breastfeed her infant. This perception affects her decisions regarding beginning and continuing breastfeeding (Pollard, 2009). It affects how she will react to any cultural or physical barriers to breastfeeding. It is measured with the Breastfeeding Self-Efficacy Scale designed by Dennis (1999) which is detailed later in this paper under the literature review.

Self-efficacy building interventions: Based on the self-efficacy concepts described above and defined for this project as:

- Mastery of past experiences or performance accomplishment: Past personal maternal breastfeeding success

- Social modeling by observation of others or vicarious experience: Role models in breastfeeding, success or failure

- Encouragement from others by verbal persuasion; encouragement may be from hospital staff, friends or family

- Physiological/emotional status; learning how to deal with postpartum pain, anxiety and fatigue to effect breastfeeding success

Maternal breastfeeding self-efficacy: Measured as an outcome in this study by the institution's subsequent increase in breastfeeding data (initiation and exclusivity of breastfeeding). 


\section{Assumptions and Limitations}

An assumption in this project was that hospitalized postpartum women in this institution would recognize the benefits of breastfeeding and strive to be successful in breastfeeding. Another assumption was that providing education to the bedside RNs on researched interventions to increase maternal confidence in breastfeeding (breastfeeding self-efficacy) would influence the increase in breastfeeding support. Since the women delivering at the institution are from diverse cultures (African American, Hispanic, Asian, Caucasian, Russian immigrant, and/or Orthodox Jew), an assumption was that aspects of ethnicity (cultural support or nonsupport) affect breastfeeding success and/or maternal breastfeeding self-efficacy.

Limitations of this project included the number of postpartum women delivering at the hospital during the month of analysis. The sample size might have been smaller or larger than anticipated, due to an unknown number of deliveries and of mothers who intend to breastfeed during the month of collection. Another limitation was that the results of this study would not be generalizable to other mothers of same ethnicities due to the study's limited sample size from one large metropolitan area. Another limitation was the short time frame of 3 months for analysis.

The interventions to increase self-efficacy done on an individual basis for each woman by staff RNs were not feasible at all times in a busy clinical setting. This meant that some women would get less individualized interventions than others from the staff. As an adjunct to this limitation a busy RN may not have documented the supportive intervention due to her work load. Another limitation was that not all of the staff (MD and $\mathrm{RN}$ ) recognized the importance of staff lactation support techniques thus not providing that support. Computer generated reports of 
individual RN EMR documentation ascertained only if the interventions were documented not always reflective of actual beside support performance.

\section{Summary}

The application of bedside lactation support interventions to increase breastfeeding initiation and exclusivity, will increase the institution's breastfeeding rates as well as demonstrate a benefit to the maternal/infant dyad.

\section{Section 2: Review of Scholarly Evidence}

\section{Literature Review}

Analysis of evidence related to a problem is done by evaluating the strengths and weaknesses of the study as well as the study outcome (Burns \& Grove, 2009). The continuum from highest to weakest evidence is commonly illustrated as a triangle, with the highest level at the top. The strongest research evidence for practice has been identified as meta analyses reviews. Randomized controlled trials (RCT) are next highest in the continuum, with correlational, descriptive and qualitative studies following. These direct further research and will be helpful with practice issues (Burns \& Grove, 2009). Expert opinions and committee reports are considered to be the weakest level of evidence. The application of evidence to practice will support quality outcomes (White \& Dudley-Brown, 2012). Analysis of literature related to breastfeeding self-efficacy and lactation support guided this study.

Hannula, Kaunonen, and Tarkka (2008) conducted a systematic review that addressed interventions to support breastfeeding, and noted that "mothers benefit from breastfeeding encouragement and guidance that supports their self-efficacy and feelings of being capable and empowered" (Hannula et al., 2008). The review consisted of 31 research articles and five review articles. The majority of the articles were quantitative. In the conclusion of the review, I 
articulated that most interventions are combinations of methods, thus making it difficult to categorically state which is best. A variety of interventions that utilize encouragement and support, as well one including peer support, would be most effective.

McQueen et al. (2011) in a randomized control trial discussed a protocol designed to increase mothers' breast feeding self-efficacy. The control group received the hospitals standard lactation support, while the intervention group received individualized support. McQueen et al. demonstrated that the members of the intervention group who received the self-efficacy interventions breastfed their infants longer and/or supplemented (with formula) their infants less. Relationships between self-efficacy and breastfeeding duration (Pollard \& Guill, 2009) were explored in a descriptive, correlational study. The authors examined associations between specific sociodemographic variables (age, smoking status, delivery type, education, enrollment in the Women's, Infants and Children program and previous breastfeeding experience), self-efficacy and breastfeeding duration. Results of the study support the use of selfefficacy as the greatest predictor for breastfeeding duration.

Kingston, Dennis, and Sword (2007) in a descriptive study examined specific strategies that would influence breast feeding self-efficacy. They studied the influence of efficacy enhancing experiences in the antepartum and postpartum period. Results from the data important for practice demonstrated that mothers who had observed breast feeding videos in the prenatal or immediate postpartum period scored significantly higher in breastfeeding confidence. Other results that may be significant for practice demonstrated a negative relationship between professional support and self-efficacy, suggesting that current strategies in use by health care professionals should be evaluated. 
A descriptive, longitudinal, cohort study was conducted by McCarter-Spaulding and Gore (2009). The authors were able to demonstrate that higher levels of breastfeeding self-efficacy in women of African descent predicted longer breastfeeding duration. Interventions to enhance selfefficacy were examined. Hatamieh (2012), in a quasi-experimental design study tested the effect of an intervention program to increase maternal breastfeeding self-efficacy in low income women. The women who were assigned to the intervention demonstrated greater increases in breastfeeding duration than did the control group.

Wheeler and Dennis (2013) described the results of testing the modified (short form) breastfeeding self-efficacy scale (BSES-SF) in a comparative descriptive design. This study was on a specific group of mothers of ill or preterm infants with no treatment or intervention. This study validated the construct and predictive ability of the scale. It did replicate previous studies regarding lack of relationship between breastfeeding self-efficacy and maternal age, education level and ethnicity. The authors also presented a unique finding of a relationship between infant birth weight and the BSES-SE score, noting that small birth weight infants may experience greater difficulty with breastfeeding.

The merit of utilizing the theory of self-efficacy in clinical practice with breastfeeding was demonstrated by the cited researchers. Maternal confidence is a strong predictor for initiating and maintaining breastfeeding. The scarcity of RCTs and a systematic review specific to self-efficacy and breastfeeding demonstrates the need for more studies. These will guide practice and assist with creating standards to address the clinical practice problem.

In addition to the research related to breastfeeding self-efficacy, articles were critically reviewed relating to a clinical practice change regarding breastfeeding support. Magri and Hylton-McGuire (2013) reported a change in the care delivery model for maternity practices. 
Barriers and solutions to support exclusive breastfeeding in a New York State Regional Perinatal Center were detailed in a case study report. Current processes were evaluated, best practices were investigated and changes were made. Pre and post change data were obtained by a random audit of charts. The change model resulted in an increase in exclusive breastfeeding in this hospital from $6 \%-44 \%$. Key elements of leadership support, education and involvement of staff at every step of the change coupled with the reporting of the data reports were cited as influential in the EBP change (Magri \& Hylton-Mcguire, 2013).

Davis, Stichler, and Poeltler (2013) described methods to increase the rate of exclusive breastfeeding, this time in a California hospital. The primary intervention in this case study was an educational intervention to integrate best practice and clinical expertise for lactation support (Davis et al., 2013). The Baby Friendly Initiative (Baby-Friendly USA, 2013) guided this article's educational initiative. The main data noted were exclusive breastfeeding rates. The rates increased from $53 \%$ exclusive breastfeeding rate to $70.4 \% 1$ year after the change project completion (Davis et al., 2013). These two case studies demonstrated the effectiveness of RN education related to breastfeeding support.

\section{Conceptual Model/Theoretical Framework}

Interventions to increase a new mother's confidence in her breast feeding success or breastfeeding self-efficacy have demonstrated significant increase in the initiation and duration (exclusivity) of breastfeeding (McQueen et al., 2011). The breast-feeding self efficacy theory (BSE-T) was developed by Dennis in 1999 based on Bandura's (1979) social cognitive theory of self-efficacy. A key component of the BSE-T is the recognition of maternal confidence as a modifiable factor to enhance breastfeeding. Interventions to increase maternal confidence in 
successful breastfeeding have been shown to increase maternal self- efficacy (Dennis, 1999; Hatamieh, 2012; McCarter-Spaulding \& Gore, 2009).

Measurement of breastfeeding self-efficacy was reported in prior research via the Breastfeeding Self-Efficacy Scale-Short Form (BSES-SF; Dennis, 1999). This scale is a 14-item questionnaire scored on a 5 point Likert- scale. The respondents select a number from 1-5 with $1=$ not at all confident and $5=$ very confident . The questions refer to elements of breastfeeding such as positioning the infant at the breast, assessing if the infant is nursing effectively, how comfortable they are with nursing in public, physical discomforts in breastfeeding, and community support in breastfeeding (Pollard \& Guill, 2009). Validity of the scale has been reported in numerous studies with diverse maternal populations (Wheeler \& Dennis, 2013). The scale was not used in this project. Instead, the interventions developed in the research to increase breastfeeding self-efficacy were utilized. These interventions were reported in Dennis (1999), McCarter-Spaulding and Gore (2009), and Hatamieh (2012).The validity of the scale has been noted in the research cited. The BSES-SF also recommends one on one nursing assessment and bedside support with lactation during hospitalization which was emphasized in this project as well.

The basis of Dennis's (1999) BSE-T was Bandura's social cognitive theory. Bandura's theory of self-efficacy (McQueen et al., 2011) explained that concepts of mastery of past experiences, social modeling by observation of others, social persuasion by encouragement from others and learning how to deal with pain, anxiety and fatigue, affect personal success. Bandura's concept of self-efficacy relates to a person's perception of their ability to succeed. Bandura's theory also believes that people can learn new information and behaviors by watching other people or from modeling other observed behavior (Cherry, 2013). The field of education 
utilizes this theory, recognizing that children model both appropriate and inappropriate behaviors. Bandura believed that aggression is also learned in this way; thus stimulating the view that this theory is relevant in criminology as well (Isom, M.D., 1998).

The BSE-T describes Bandura's concepts in the light of maternal breastfeeding success. Bandura's theory notes that the key influence on self-efficacy is mastery of an experience. This experience will affirm that an individual is able to perform a behavior and learn from it. In breastfeeding, this correlates with a mother's success with initiating breastfeeding, which predicts further success with breastfeeding duration.

Other concepts of self- efficacy are those of modeling observed behavior and social persuasion. When a woman has been exposed to other women breastfeeding in a relaxed, informal setting, and has been supported in breastfeeding by encouragement from others, breastfeeding self- efficacy will be promoted (Dennis, 1999). Lastly, improving the physical status or reducing a breastfeeding mother's stress levels will enhance breastfeeding self-efficacy (Dennis, 1999). Administering analgesics to the mother to alleviate the uterine discomfort that occurs in the early postpartum days with breastfeeding will break the association of pain and breastfeeding (Ibid). Getting into a comfortable position, drinking a favorite beverage, listening to music or TV while breastfeeding, will associate rest and relaxation with breastfeeding (Ibid). These interventions will assist with breastfeeding self-efficacy. In breastfeeding, this theory of modeling and positive reinforcement, as well as encouragement from others, has been associated with a mother's success with initiating breastfeeding. This, in turn predicted further success with breastfeeding exclusivity (Cherry, 2013). 


\section{Section 3: Approach}

This project, to increase initiation and exclusivity of breastfeeding, was accomplished through an intervention educating bedside RNs on the importance of bedside lactation support. The RNs received the education and demonstrated competency in performing the support interventions upon the breastfeeding mother. These interventions were expected to increase the breastfeeding initiation and exclusivity rates in the hospital. The hospital breastfeeding rates (initiation and exclusivity) were compared pre-intervention and post-intervention.

\section{Project Design/Methods}

The increasing breastfeeding rates program was designed as an evidenced based practice change of increased bedside RN lactation support. It was based upon education and involvement of the institution's current Lactation Operations Group (LOG) aligned with education of the bedside RN. It was designed as a project improvement project with the RN education as the intervention. The percentages of breastfeeding initiation and exclusivity noted at the end of the project reflect the success of the project.

The LOG membership includes representatives of the bedside nursing staff, lactation consultants, a nursing information analyst and the Perinatal (L\&D, MB, NICU) nursing leadership. A pediatrician and neonatologist are ad-hoc members who serve in advisory positions. I am a Board Certified Perinatal Clinical Nurse Specialist (CNS-BC), and facilitate the primarily postpartum and nursery RN membership. Tenants of EBP and quality improvement are central to the agenda of the committee. Education related to improving the breastfeeding rates is given. Changing the culture of the patient population and the other staff members regarding the significance of breast milk feeding coupled with the negative aspects of supplementation are priorities of the group as well. 
The vision for the LOG is to champion a culture of human milk preferred through designing and supporting structures, processes, education, and advocacy for exclusive breastfeeding of infants throughout mother/newborn hospital stay. The project to increase breastfeeding rates reflected that vision. The goal of the LOG is to meet the Healthy People 2020 target for breastfeeding initiatives: Breastfeeding initiation at $81.9 \%$ and exclusive breastfeeding at discharge to $85.8 \%$. (Institutional current rates: $55.49 \%$ and $63.16 \%$ as displayed in Figure 1 below). This project mimicked that goal as well.

\section{Institutional Measurement \& Monitoring of Breastfeeding Benchmarks}

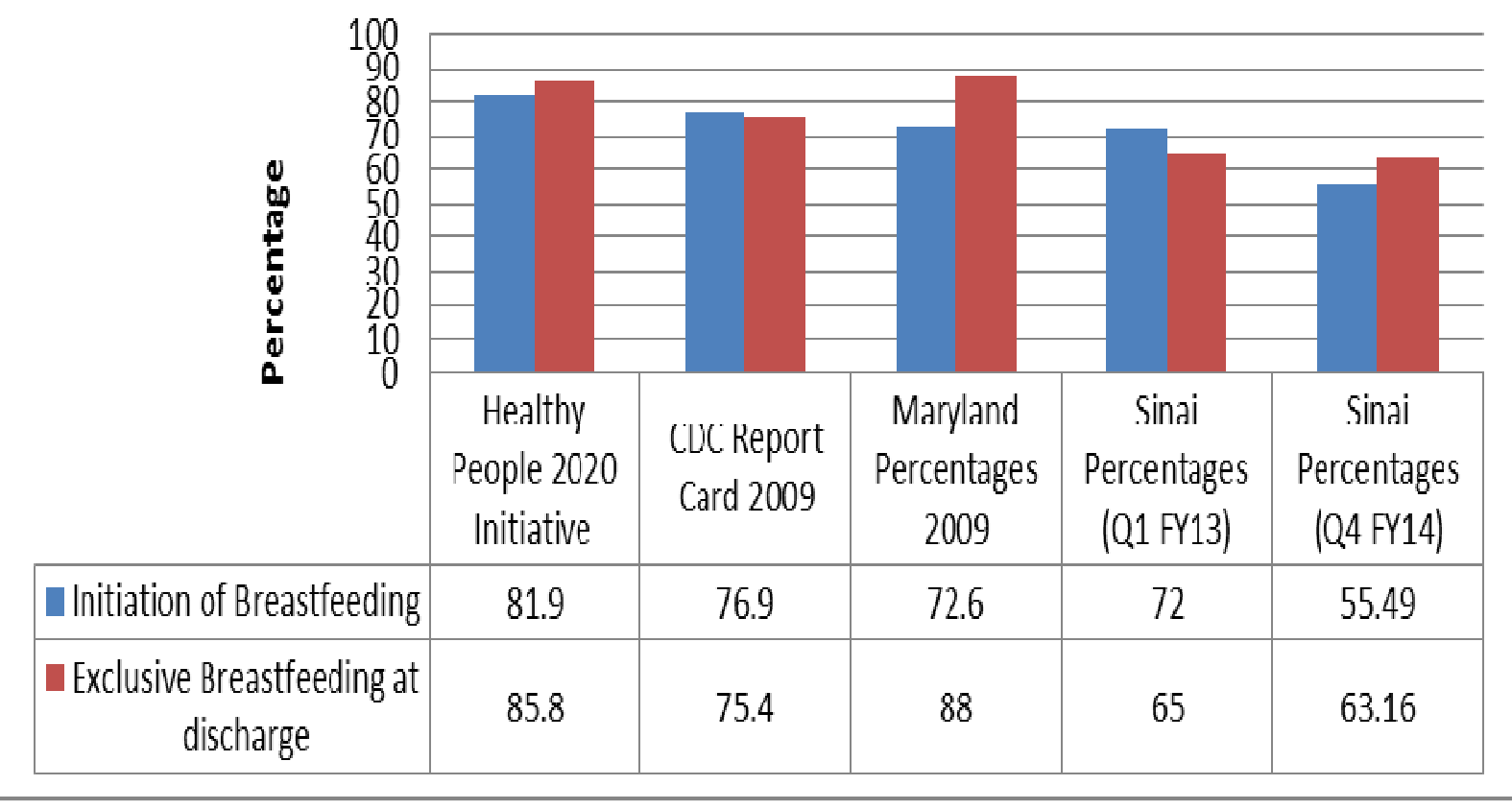

Figure 1. Measurement and monitoring data.

Interventions to increase maternal self-efficacy have been identified in literature (Dennis, 1999, McCarter-Spaulding \& Gore, 2009 and Hatamieh, 2012).Increasing maternal self - 
efficacy in breastfeeding has been shown to increase breastfeeding rates. One hundred percent of the seventy nurses on staff in the Perinatal Units (L\&D, Postpartum [PP] and Newborn Nursery) were educated on lactation support. This was done by combining pathophysiology of lactation and scripting techniques related to exclusivity of breast milk feeding, with maternal breastfeeding self-efficacy concepts.

The timeline for the DNP project to show an increase in initiation and exclusive breastfeeding was 3 months. The first month consisted of the LOG education and planning for the intervention project. The second month an educational module was presented to the staff by the IBCLCs and myself as the CNS. The educational module consisted of concepts of maternal self-efficacy aligned with successful breastfeeding, breastfeeding pathophysiology, lactation support interventions and EMR documentation. The objectives of the module are noted in Appendix B.

After completion of the educational module the RNs were to shadow the IBCLCs to observe the interventions, and then perform a return demonstration. The RN Breastfeeding Intervention Competency Checklist (Appendix C) was to be used to document completion of the training. These checklists and shadowing were to be initiated in the projects third month to become part of each RNs professional portfolio. Annual audits to ensure that RNs are competent in assisting mothers to be successful in breastfeeding their infants were to be done.

Documentation of activities to increase breastfeeding rates aligned with sources of selfefficacy are detailed in Appendix D with illustration of the documentation of these interventions. A monthly report listing compliance with electronic medical record (EMR) documentation was generated electronically as an audit. These audits assist with targeted remedial education as needed, and are overseen by the IBCLCs, the LOG and nursing leadership. 
Data are collected quarterly from existing EMR reports and reported externally to the Joint Commission as part of the Perinatal Core Measures (initiation of breastfeeding within one hour after delivery and exclusive breastfeeding while hospitalized). Internally (to the institution) the data is reported to the LOG and to the hospitals Performance Management Council (PMC).The LOG's involvement in the proposed interventions to increase rates is included as part of the action plan to the PMC for compliance with the Perinatal Core Measures.

After the education to the RN staff, the LOG oversaw computerized audits confirming completion of electronic documentation (Appendix C), which identified opportunities for improvement. Educational updates related to any identified missing elements are given to the staff nurses by the LOG. These updates are prompted by the EMR audits and ensure staff compliance and competency regarding documentation. The lactation support education and shadowing checklist is now given during orientation to new hires, thus assimilating it into unit culture.

The process for the educational intervention was as follows:

1. Mandatory $21 / 2$ hour education to the RN staff (Objectives noted in Appendix B)

2. Shadowing/observation of the IBCLC with completion of the competency checklist (Appendix C)

3. Audit of EMR documentation (Appendix D)

4. Ongoing monitoring of breastfeeding data (initiation and exclusive breastfeeding as outlined in the run chart, Figure 2) with targeted remedial education as needed.

\section{Population Selection Process}

The organization was founded and supported by the Jewish community in 1866 and "continues to be sensitive to the needs of Jewish patients and staff" (Sinai Hospital, 2013). An 
adjoining location to the institution is the second largest area of Jewish residence in the city, home to 13,000 Jewish people living in 3,850 Jewish households (The Associated, n.d.).

The primary service area of the institution was noted by examining the zip codes of discharged patients (Sinai Hospital, 2013). The racial composition and income distribution of the predominant zip codes of discharges of this institution reflect the segregation and income gap characteristic of this metropolitan region. Those zip codes, which include the zip code of the hospital, have the above mentioned Orthodox Jewish population, but also notes predominantly African American residents, with an increasing Hispanic population, and reflect the racial composition and poverty representative of this section of the city (Sinai Hospital, 2013). The demographics note an area with a below average median family income and above average rates for unemployment and other social determinants of poor health; i.e. food deserts (Sinai Hospital, 2013).

The importance of the hospital population as Jewish is noted for an understanding of cultural norms of the delivering mothers. Many Orthodox Jewish mothers have large households. Their infants may be kept in the hospital nursery except for feedings and they may resist rooming in, especially at night. This affects supplementation rates, as research has noted that no separation between mother and newborn is a factor in exclusive breast feeding (Eidman, 2011).

The breastfeeding rates among socially disadvantaged women are noted to be lower than the national average as discussed earlier (McQueen et al., 2011). Research has revealed that black women breastfeed at a lower rate than white women (McCarter-Spaulding \& Gore, 2009, as cited by Eidmann, 2011). This is significant for this project due to the depressed economy and diversity of the population surrounding the proposed project site (Sinai Hospital, 2013). 
The institution has 467 acute beds, 35 newborn bassinets and 18 Neonatal Intensive Care beds, delivering approximately 2200 infants per year, or approximately 170 deliveries a month. It is a teaching institution, with 16 obstetrical residents and 12 pediatric residents. It is a Perinatal Referral Center, with a high risk Maternal Fetal Medicine clinic on site located adjacent to the Perinatal (L\&D, Mother/Baby, and NICU) Service Units. The target population was hospitalized immediate postpartum women in a coastal mid-Atlantic inner city hospital who desire to breastfeed. A convenience sample of one month's breastfeeding rates was compared retrospectively (pre-intervention) with one month's rates post-intervention.

Comparative data describes the difference between the studied population and state and national groups (Kettner, Moroney \& Martin, 2013). In this project, the data for breast feeding initiation and duration for this institution was compared with national and state data (Figure 1). This institution's rate of initiation of breastfeeding and exclusive breastfeeding at discharge was known to be below the national and state benchmarks (CDC, 2011). Comparative reports of data are an integral part of this breastfeeding program and will be used to demonstrate the intervention's success rate.

\section{Data Collection and Analysis}

The data point of breastfeeding initiation within one hour of birth is electronically documented at time of first breastfeeding or at time of first breast pumping correlated with delivery time. The data point of exclusive breastfeeding is electronically documented by the RN who documents infant intake as either the minutes at breast or the amount of formula. Demographic data (age, marital status, and ethnicity) is currently collected via an inpatient electronic admission system. Biological demographic data are entered by the RN into the EMR obstetric admission data base and details maternal gravida and parity, infant feeding method 
preferred (breast/formula). The demographic data were de-identified with descriptive statistics done on the data. Correlational analysis of the demographic data were not in the scope of this project, however may be beneficial for future studies in light of population health.

RN EMR documentation was noted in the project. The data is gathered per the documentation in Appendix D and compiled in an existing report (the Joint Commission Perinatal Core Measures, CDC), as noted earlier. Table 3 outlines the data collection points. Table 4 notes the EMR data collection points for the report generated to reflect the CDC outcome measures (percentages of newborns breastfed within first hour of life) and the Joint Commission outcome measures (exclusive breastfeeding while still hospitalized).

Table 3

Data Collection Points

\begin{tabular}{ll}
\hline Admission Intake: Demographic Data & EMR Data Collected: Objectives of the Project \\
\hline Age & Type of delivery \\
Race & Date/Time of Delivery \\
Marital status & Date/Time of first breast feeding \\
Gravida & Intake: Minutes = Breast \\
Parity (Full term, Pre term) & Milliliters = Bottle \\
Desired Feeding Method (Breast/Bottle) & Date/Time Pumping \\
\hline
\end{tabular}

Table 4

Electronic Medical Record (EMR) Breastfeeding Data Collection

\begin{tabular}{|c|c|c|c|}
\hline $\begin{array}{l}\text { Number of singleton } \\
\text { births (monthly) } \\
\text { admitted to Newborn } \\
\text { Nursery }\end{array}$ & $\begin{array}{l}\text { Number of newborns } \\
\text { breastfed within the first } \\
\text { hour of life }\end{array}$ & $\begin{array}{l}\text { Newborns exclusively } \\
\text { breastmilk fed (no } \\
\text { formula } \\
\text { supplementation) }\end{array}$ & $\begin{array}{l}\text { Single born newborns } \\
\text { discharged alive from the } \\
\text { newborn nursery }\end{array}$ \\
\hline
\end{tabular}

The Nursing Information Specialist (NIS) for the Women \& Children's Division collects a report derived from the EMR data points. The breastfeeding data is analyzed according to the Joint Commission directions. This involves the numerator of newborns fed breast milk only since 
birth and the denominator single born newborns discharged alive from hospital. Exclusion factors for this Joint Commission Core Measure are multiple births and NICU admits. From this analysis, the percent of infants who initiate breastfeeding, as well as the percent of infants exclusively breastfed during hospitalization is reported (Table 2 outcome measures).

\section{Protection of Human Subjects}

In compliance with the procedures and policies that govern the protection of human participants in research studies, approval to conduct the study was obtained from the Institutional Review Board (IRB) of Walden University (Approval \#05-23-14-0320766). Additionally, the IRB of Lifebridge Health issued a certificate of exemption (\#2135) to conduct the study on deidentified data.

\section{Project Evaluation Plan}

Program evaluation determines the impact of the program. It provides feedback on outcomes and assists with determining the effectiveness of the project (Kettner, Moroney, \& Martin, 2013). The Rosswurm and Larrabee (1999) EBP model guides this project. However performance improvement plans are incorporated into the project. These include setting specific, measurable, achievable, relevant and time-framed (SMART) goals. The goals for this project were earlier stated in Table 1 as demonstrating an increased initiation of breastfeeding immediately after birth and demonstrating an increase in exclusive breastfeeding during the newborn's entire hospital stay. The time frame for accomplishing the goal was the project duration: 3 months.

A run chart was used to track progress of the project over time. This data detects patterns and notes when interventions occurred. A run chart with pre-intervention outcome data points for the Joint Commission (JC) is displayed in Figure 3 below 


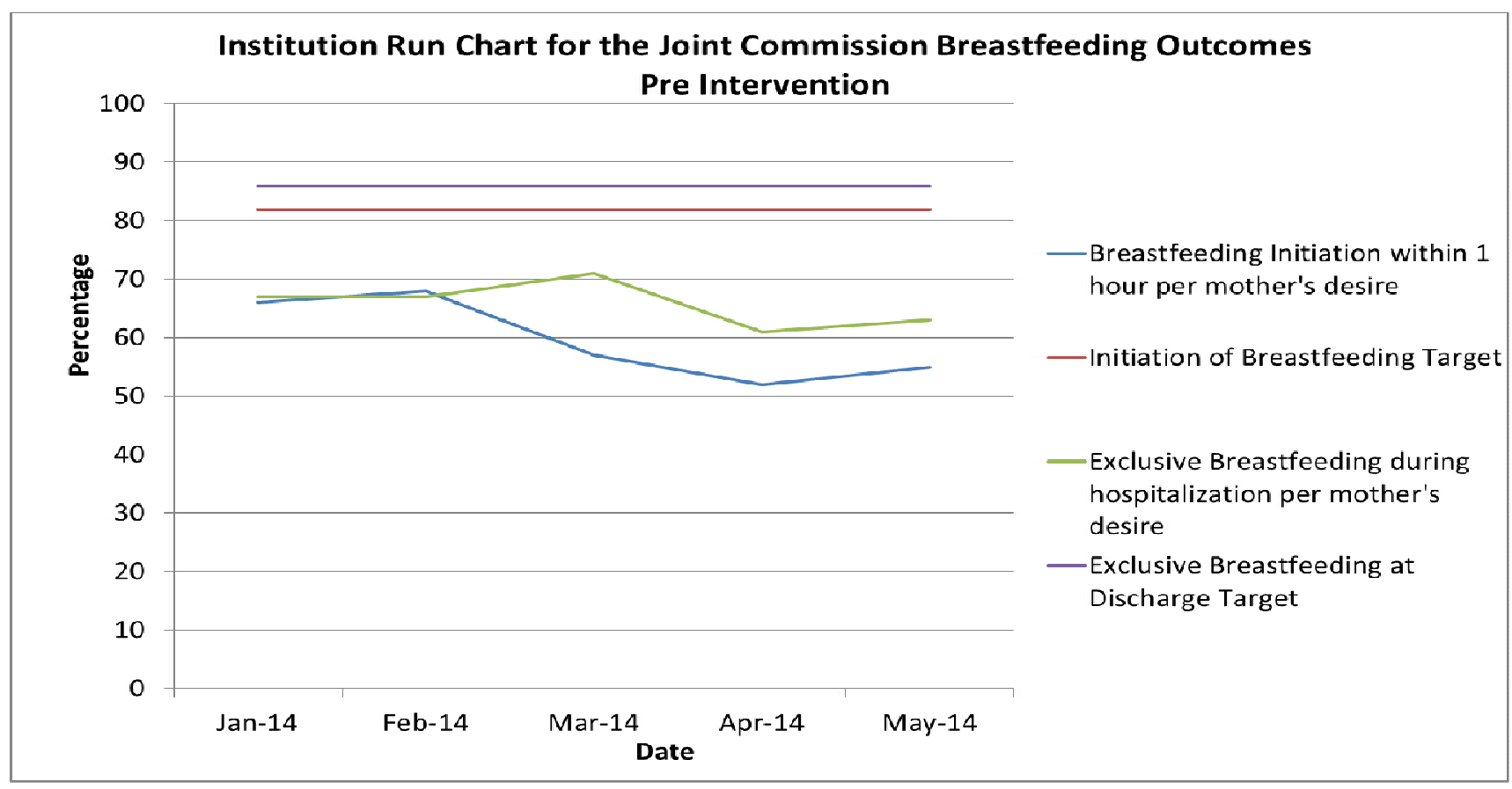

Figure 2: Run Chart for the Joint Commission Breastfeeding Outcomes Pre Intervention Communicating the hospital breastfeeding data is a feedback mechanism for performance improvement. It is shared internally to the LOG as well as to the perinatal nursing units, the $\mathrm{OB}$ medical staff department meeting and the larger hospital performance management council. It is presented at the community level, via the institutions' partnership community (i.e. Park Heights; a Federally Qualified Health Center). Presenting the information (benchmarked data, interventions, and institution/community data) encourages a shared vision (Hampton, C., 2011). The Maryland Breastfeeding Coalition is a partner with the LOG, and is a part of the community audience for a presentation/report, as is the B'More Healthy Babies campaign and the March of Dimes local chapter.

Ethical discussions for this project included maternal autonomy. Women are allowed to make their own decision regarding breastfeeding, and are allowed to change their minds if they decide to not breastfeed. The LOG believes that education to the woman prenatally as well 
as to the community about the benefits of breastfeeding for the woman and infant, will positively impact the decision to breastfeed. This is included in the verbal persuasion concept of selfefficacy. The staff RNs and the IBCLCs endeavor to not make the woman feel guilty if she decides to supplement her infant while hospitalized; however want to ensure that women understand the implications of early supplementation. This is reinforced by the documentation of scripting in the EMR (Appendix D).

Step VI of the EBP model of Rosswurm and Larrabee (1999) is to integrate and maintain the change in practice. Engaging clinical nurses in quality performance will be successful if they are informed about the data and able to translate that data into ways to improve patient care (Albanese et al, 2010). This performance improvement project introduced nurses at the bedside to benchmarked data from national and state levels. It also presented a systematic process to analyze current practice with evidence based best practice. The Six Sigma approach to 1) define a problem 2) measure the process in need of improving, 3) analyze the cause and effects of the issue 4) improve and then 5) maintain/sustain the improvement, aligns with the six step EBP model of the organization.

The program is sustainable with engaged stakeholders, both internally and externally. Internal stakeholders include the staff members of the LOG (RN and MD) as well as the newly educated bedside staff RN. External stakeholders include the community breastfeeding support group, the Maryland Breastfeeding Coalition and B'more Healthy Babies. The primary stakeholders for this project are the mother/infant dyad. 


\section{Summary}

The American Academy of Pediatrics (2012) has noted that with "the documented shortand long-term medical and neurodevelopmental advantages of breastfeeding, infant nutrition should be considered a public health issue and not only a lifestyle choice". Initiation of this program to increase breastfeeding initiation and exclusivity via the $\mathrm{RN}$ educational intervention to increase maternal breastfeeding self-efficacy, demonstrates a measurable change in health outcomes. 
Section 4: Findings, Discussion, and Implications

\section{Summary of Findings}

Seventy Perinatal Unit bedside staff RNs ( $100 \%$ of the RN staff) completed a mandatory educational intervention to increase institutional rates of breastfeeding initiation and exclusivity. The education was intended to facilitate bedside lactation support. The educational module consisted of viewing the Breastfeeding Class video that parents view in Childbirth Class, discussion of the video, lactation pathophysiology and concepts of self-efficacy related to breastfeeding. This was aligned with instruction and discussion of scripting to assist parents with successful breastfeeding (Appendix B). Eighteen classes of the $2 \frac{1}{2}$ hour module were held during the month of June 2014.

Descriptive statistical analysis was run on the earlier discussed data points (Table 3) gathered electronically from the registration data base from May 2014 through July 2014. The average age, gravida, and parity (full term and preterm) of delivered mothers monthly was noted. The percentages of the marital status, race, and type of delivery were also noted on monthly deliveries. This was done via SPSS ${ }^{\circledR}$ analysis of the electronic medical record (EMR). Table 5 demonstrates detail of the descriptive demographic analysis. The data demonstrated that the demographics in the pre-intervention and post-intervention time frames (1 month each) were similar. 
Table 5.

Descriptive Demographic Statistics

\begin{tabular}{|c|c|c|c|c|}
\hline \multirow[t]{2}{*}{ Demographic Data } & \multicolumn{2}{|c|}{$\begin{array}{c}\text { May } \\
(\mathrm{N}=\mathbf{2 0 3})\end{array}$} & \multicolumn{2}{|c|}{$\begin{array}{l}\text { July } \\
(N=220)\end{array}$} \\
\hline & $n$ & $\%$ & $n$ & $\%$ \\
\hline Asian & 10 & 4.9 & 11 & 5 \\
\hline Black or African American & 89 & 43.8 & 92 & 41.8 \\
\hline Declined To Answer & 20 & 9.9 & 17 & 7.7 \\
\hline Multiple & 1 & 0.5 & 1 & 0.5 \\
\hline $\begin{array}{l}\text { American Indian or Alaskan } \\
\text { Native }\end{array}$ & 0 & 0 & 2 & 0.9 \\
\hline $\begin{array}{l}\text { Native Hawaiian, Other Pacific } \\
\text { Islander }\end{array}$ & 1 & 0.5 & 0 & 0 \\
\hline White & 82 & 40.4 & 97 & 44.1 \\
\hline \multicolumn{5}{|l|}{ Marital Status } \\
\hline Divorced & 2 & 1 & 1 & 0.5 \\
\hline Married & 111 & 54.7 & 134 & 60.9 \\
\hline Single & 89 & 43.8 & 83 & 37.7 \\
\hline Declined To Answer & 1 & 0.5 & 2 & 1 \\
\hline \multicolumn{5}{|l|}{ Type of Delivery } \\
\hline Cesarean Section & 53 & 26.1 & 57 & 25.9 \\
\hline Vaginal & 148 & 72.9 & 161 & 73.1 \\
\hline not charted & 2 & 1 & 2 & 1 \\
\hline Age (mean) & 27.8 & & 28.63 & \\
\hline Gravida (Mean) & 3 & & 3 & \\
\hline Para (full term) Mean & 2 & & 2 & \\
\hline
\end{tabular}

The results for the project outcomes (Joint Commission [JC] core measures related to breastfeeding) are reported in Table 6 . The formula is directed by the JC and is calculated by: numerator of newborns fed breast milk only since birth over the denominator single born newborns discharged alive from hospital. Figures 4 and 5 are graphic displays of the project outcome measure results. The outcome measures demonstrated an increase in scores for breastfeeding. The initiation of breastfeeding within the first hour of life score rose from $55.4 \%$ 
to $62.3 \%$ in the month after the intervention, while the exclusivity of breastmilk feeding while in the hospital rose from $63.1 \%$ to $70.78 \%$.

Table 6.

Post Intervention Joint Commission Data Analysis

\begin{tabular}{|c|c|c|c|c|}
\hline \multirow[t]{2}{*}{ Month } & $\begin{array}{l}\text { Babies to } \\
\text { Newborn Nursery }\end{array}$ & Breastfeeding Initiation & $\begin{array}{l}\text { Babies discharged alive } \\
\text { from Newborn Nursery }\end{array}$ & $\begin{array}{l}\text { Exclusive breastfeeding } \\
\text { at discharge }\end{array}$ \\
\hline & $\mathbf{N}$ & $\%$ & $\mathbf{N}$ & $\%$ \\
\hline May & 175 & \begin{tabular}{|l|}
55.4 \\
\end{tabular} & 175 & 63.1 \\
\hline July & 199 & 62.3 & 199 & 70.8 \\
\hline
\end{tabular}

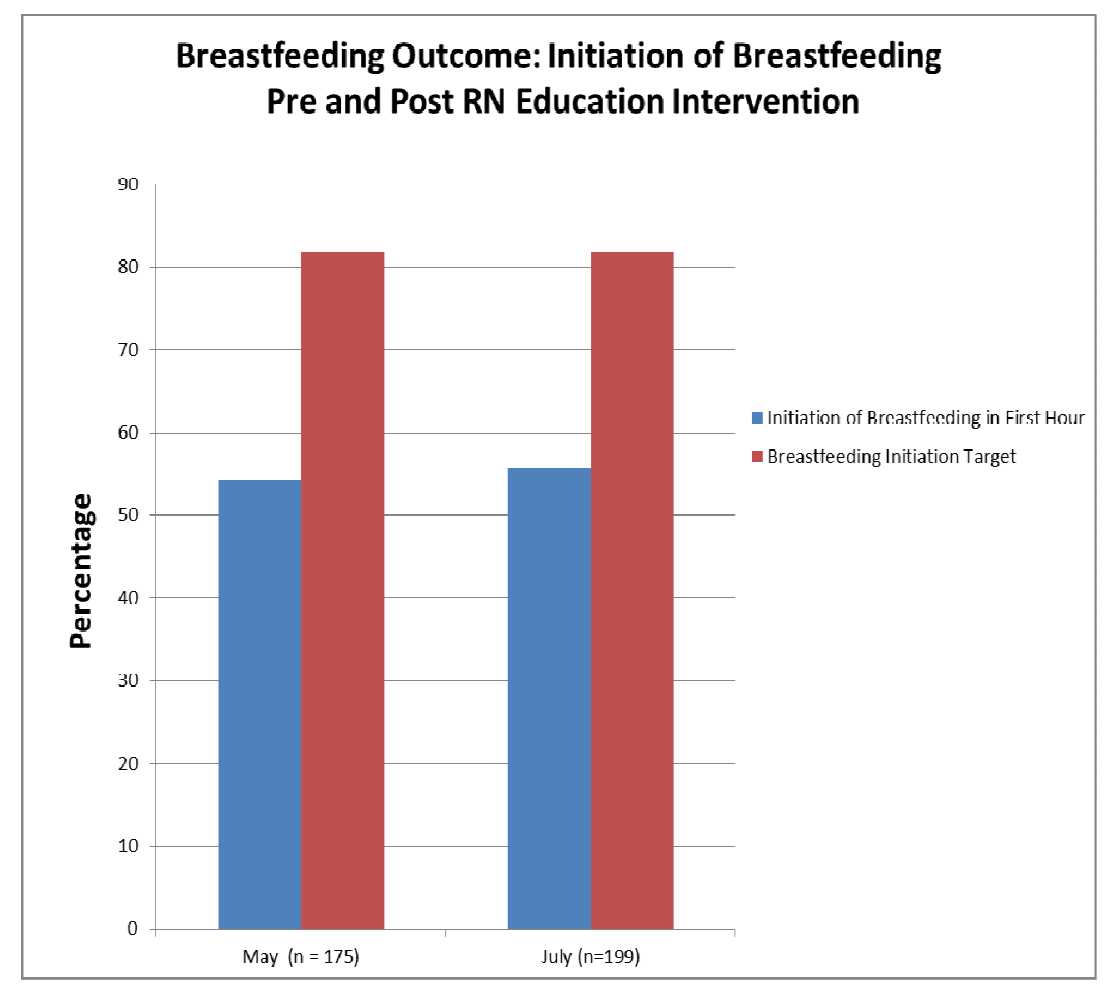

Figure 3. Post Intervention Initiation of Breastfeeding in First Hour Outcomes 


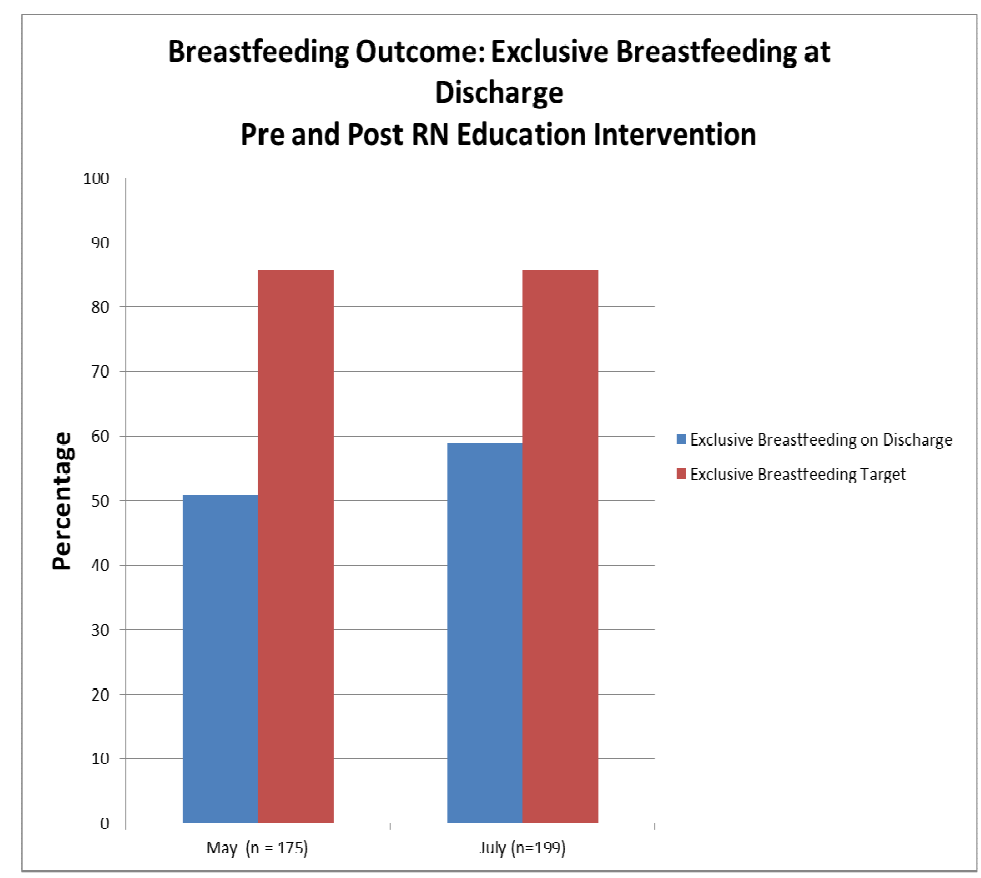

Figure 4. Post Intervention Exclusive Breastfeeding on Discharge Outcomes

Chi-squared analysis was performed via SPSS ${ }^{\circledR}$ Version 21 to compare statistical significance of both outcomes. Breastfeeding Initiation within the first hour (Did Breastfeed) of life was coded 1, with Did Not Breastfeed within the first hour coded 0. Breastfeeding Exclusivity (no supplementation) was coded 1, No Breastfeeding Exclusive coded 0. Tables 7 and 8 demonstrate that while an increase was noted in both outcomes measured, they were statistically non-significant. Breastfeeding Initiation within one hour Chi-Square was 0.084 which was less than 3.84 (1df). Breastfeeding Exclusivity Chi-Square was 2.37 which was less than $3.84(1 \mathrm{df})$.

Table 7

Chi-Square Analysis: Breastfeeding Initiation Within First Hour of Life

\begin{tabular}{|l|cc|c|}
\hline Experimental Condition & \multicolumn{2}{|c|}{ Outcome of Study } & Totals \\
& Did Breastfeed & Did Not Breastfeed & \\
\hline May (Pre-intervention) & 95 & 80 & 175 \\
\hline July (Post-intervention) & 111 & 88 & 199 \\
\hline
\end{tabular}




\begin{tabular}{|l|ll|l|}
\hline Total & 206 & 168 & 374 \\
\hline
\end{tabular}

Table 8

Chi-Square Analysis: Breastfeeding Exclusivity

\begin{tabular}{|c|c|c|c|}
\hline \multirow{2}{*}{ Experimental Condition } & & f Study & \multirow[t]{2}{*}{ Total: } \\
\hline & Exclusive & No Exclusive Breastfeeding & \\
\hline May (Pre-intervention) & 89 & 86 & 175 \\
\hline July (Post-intervention) & $11^{\prime}$ & 82 & 199 \\
\hline Total & 20 & 168 & 374 \\
\hline
\end{tabular}

\section{Discussion of Findings}

Black women breastfeed at a lower rate than white women (McCarter-Spaulding \&

Gore, 2009, as cited by Eidmann, 2011) which was expected pre-intervention to be significant as that the project site is situated in a racially diverse region (Sinai Hospital, 2013). The project demographic data demonstrated a fairly even distribution of White and Black/African American women (Table 5), thus this was not a significant factor. Research reports that breastfeeding is more common in older, married women (McDowell, Chia-Yih \& Kennedy Stevens, 2008; as cited in Lewallen \& Street, 2010). The project demographic data revealed a higher percentage of married women in the project with the average age between 27 and 29 years of age. The cesarean section rate of the project institution is $25-26 \%$ which is below the national average of $32 \%$ (CDC, 2011). Pain control can be more difficult in the post- operative cesarean section patient, with a result in less exclusive breastfeeding (Kingston \& Dennis, 2007). The average gravida/parity of the women in the project was three pregnancies with two previous deliveries. Breastfeeding intent and subsequent success is reportedly higher in women who have prior experience in breastfeeding (Kingston \& Dennis, 2007). The demographic data analyzed in this project (Table 5) reflected reported research. 
The intervention, consisting of the mandatory educational sessions with staff RNs emphasizing bedside lactation support and scripting to discourage formula supplementation, was the only significant variants in the period of data analysis. Although Chi Square analysis was not statistically significant, the frequency of mothers initiating and maintaining exclusive breastfeeding increased with the intervention (education and scripting). This demonstrates clinical significance.

The Lactation Operations Group discussed that the nurses may not recognize or document the initiation of breastfeeding during skin to skin. Monitoring the data as well as continuing education to the staff RNs are integral factors in evaluating and sustainment of the project.

\section{Implications}

The implications of this educational intervention on bedside lactation support were positive. Not only were the scores for initiation and exclusivity of breastfeeding increased, the IBCLC's were able to start spending more time with breastfeeding consults for issues, rather than seeing each breastfed mother individually. The staff RNs became more engaged in lactation support and felt more comfortable with a standardized breastfeeding advice and care model. The lactation support now starts on admission with the L\&D RNs who begin the conversation about breastfeeding, explaining immediate skin to skin and initiation of breastfeeding within the first hour. The Postpartum/Nursery RNs are continuing the lactation support by attempting to keep the mother and baby together via the "rooming in" model. If the mother becomes fatigued during the night and asks for infant supplementation, the RNs are more comfortable with the scripted advice; for example stating that formula decreases milk supply (WHO, 2011). 
Breastfeeding has been shown in literature to decrease infant health issues such as allergies, diabetes, respiratory and gastric illnesses (American Academy of Pediatricians, 2011). Future research is needed to ascertain the readmission rates for these issues in the community breastfed infants vs those who weren't breastfed. Maternal benefits from breastfeeding their infants have been shown as well. These include a decrease in ovarian and breast cancer (World Health Organization, 2013). Examining the rates of these cancers in those women who breastfed vs those who didn't would be of interest.

Social change will be evident in reduction of the above named acute and chronic illnesses. Economic benefits for society would include the reduction or elimination of physician visits and hospitalizations from these illnesses, as well as parental economic benefits from reducing formula costs.

\section{Strengths and Limitations}

Strengths of this project include an existing engaged grassroots committee (LOG). Using the Rosswurm and Larrabee (1999) framework to change practice, the LOG was able to recognize the issue of low breastfeeding scores. They were guided by myself as the CNS in an investigation of best practices and were supportive of the educational module. The IBCLCs were an added strength. Their expertise in breastfeeding support as well as their coaching of the staff contributed to the validity of the intervention.

A major limitation to the project was the birth log data base. Originally it was believed that this data base would have the monthly demographic data desired for analysis. It was discovered that the data base is by discharge date, thus the delivery dates were not organized by month. This created a need for manual manipulation of the log to create the monthly demographic data. The discharge date data, however, was what is necessary to compute the JC 
measure of exclusivity of breastfeeding at time of discharge. The other limitation was that the demographic data is collected in a different software application than the registration data (Meditec ${ }^{\circledR}$ versus Cerner), necessitating more manual manipulation of data into another spread sheet for analysis. The two systems also gave different total number of patients per month. With the update of the registration system to the same system (Cerner) this will rectify this dilemma. Closer audits of the registration numbers and the birth log will address this as well. 


\section{Analysis of Self}

Evidence based practice and the nursing process guide this author's philosophy of life. Identifying goals (for patient, nursing, and/or for self), researching best practices and linking that best practice to an intervention and best outcomes is essential. Translation of that evidence to improve clinical outcomes is tantamount to nursing practice. In the course of this project, I have developed and honed skills to guide, coach and mentor others in the quest of interventions to positively influence quality outcomes for mother and infant via breastfeeding.

This project has expanded my realization of the influence a transformational leader may have on the organization. Many committees in Magnet organizations are comprised of bedside nurses. White and Dudley-Brown (2012) noted that many bedside nurses do not have the foundation for evaluating evidence and prefer social learning to rate practice. My role as a DNP leader is to mentor and model translation of research and evidence into beside practice. Supplying baseline metrics prior to this intervention as well as after the intervention, contributed to staff comprehension of evidence based practice. Staying informed with new research as well as completing literature reviews of evidence when faced with practice issues supports my leadership.

This project has taught me that evaluation of descriptive statistics for projects is vital. Hutt (2012; as cited in White \& Dudley-Brown, 2012) noted that "data analysis is an important component of outcome assessment". In this project, descriptive demographic analysis reinforced that the projects outcome was related to the intervention, since the demographics of the population before and after the intervention were so similar.

Future professional growth will include further assimilation of the American Association of Colleges of Nursing (AACN) essentials of Doctoral Education for Advanced 
Nursing Practice (2006 [Appendix E]). Throughout the course of the Doctor of Nursing Practice (DNP) curriculum, these eight essentials have influenced my studies. Each essential will be continually integrated into my future career path as well.

\section{Summary and Conclusions}

This project to increase the initiation and exclusivity of breastfeeding in the hospitalized postpartum woman was successful in the first month post intervention. Outcome measures demonstrated an increase in scores of breastfeeding initiation (55.4\% to $62.3 \%)$ and in breastfeeding exclusivity $(63.16 \%$ to $70.18 \%)$. Chi-square analysis was not statistically significant; however progression towards the benchmarks was made. The project was accomplished by an educational intervention to standardize bedside lactation support facilitated by this author.

Success was dependent upon utilization of an EBP model (Rossworm \& Larrabee, 1999) as a framework. It incorporated specific interventions related in numerous studies based on Dennis's Theory of Breastfeeding Self Efficacy (1999), which was grounded in Bandura's social cognitive theory of self- efficacy (1977, as cited by McQueen et al., 2011).

Maintaining success of this project will be demonstrated by sustaining the engagement of the bedside RN in lactation support. Audits of documentation with continued dissemination of the breastfeeding outcome scores will encourage discussion and commitment. Incorporation of standardized bedside lactation support interventions into practice will increase positive patient outcomes.

This project illustrated success in translating best practice to the bedside. These evidenced best practices for lactation support have the potential to improve health outcomes not only for the hospitalized maternal/infant dyad but for society as well. 


\section{Section 5: Scholarly Project}

White and Dudley-Brown (2012) discuss dissemination of translation of evidence as essential to change in care. "Dissemination is the communication of clinical, research, and theoretical findings for the purpose of transitioning new knowledge to the point of care" (Brown \& Schmidt, 2009, as cited in White \& Dudley-Brown, 2012). Dissemination takes many forms. It may be internally at clinical inservices or grand rounds, or externally at conferences. The traditional methods for dissemination are posters, podium presentations and articles.

Appendix F is a PowerPoint presentation to the Women \& Children's Leadership team of the project institution. Appendix G highlights an abstract submitted for an external EBP/Research Symposium. The more a translation is disseminated, the more successful and wide spread the change in practice will be (White \& Dudley-Brown, 2012). 


\section{References}

Albanese, M. P., Evans, D. A., Schantz, C. A., Bowen, M., Disbot, M., Moffa, J. S.,...

Polomano, R. C. (2010). Engaging clinical nurses in quality and performance improvement activities. Nursing Administration Quarterly, 34(3). doi: 10.1097/NAQ.0b013e3181e702ca.

American Academy of Pediatrics. (2012). Breastfeeding and the use of human milk. Pediatrics, 129 (3). doi: 10.1542/peds.2011-3552

American Academy of Pediatricians and the American College of Obstetricians and Gynecologists. (2009). Guidelines for perinatal care $\left(6^{\text {th }} \mathrm{ed}\right)$. Washington D.C.: Author.

Baby-Friendly USA. (2013). Retrieved from http://www.babyfriendlyusa.org/

Burns, N., \& Grove, S. K. (2009). The practice of nursing research: Appraisal, synthesis, and generation of evidence ( $6^{\text {th }}$ ed.). St. Louis, MO: Saunders.

Centers for Disease Control and Prevention. (2011). Breastfeeding report card. Retrieved from http://www.cdc.gov/breastfeeding/pdf/2012BreastfeedingReportCard

Cherry, K. (2013). Social learning theory: An overview of Bandura's social learning theory. Retrieved from http://www.psychologyabout.comod/developmentalpsychology/a/sociallearning.htm

Davis, S.K., Stichler, J.F., \& Poeltler, D. M.(2013). Increasing exclusive breastfeeding rates in the well-baby population. Nursing for Women's Health, 16(6). doi:10.1111/j.1751486X.2012.01774.X

Dennis, C.L. (1999). Theoretical underpinnings of breastfeeding confidence: A self-efficacy framework. Journal of Human Lactation, 15(3). doi:10.1177/089033449901500303. 
Eidman, C. K. (2011). Enhancing breastfeeding self-efficacy through prenatal education. Master of Arts in Nursing Theses. Paper 31. Retrieved from http://sophia.stkate.edu/ma nursing Hampton, C. (2011a). Communicating information to funders for support and accountability. Retrieved from the Community Tool Box: http://ctb.ku.edu/en/tablecontents/sub section main 1376.aspx

Hampton, C. (2011b). Providing feedback to improve the initiative. Retrieved from the Community Tool Box: http://ctb.ku.edu/en/tablecontents/sub_section_main_1374.aspx

Hannula, L, Kaunonen, M., \& Tarkka, M. (2007). A systematic review of professional support interventions for breastfeeding. Journal of Clinical Nursing, 17(3),.1132-1143 doi: 10.1111/j.1365-2702.2007.02239.x

Hatamieh, W. (2012). Prenatal breasteeding intervention program to increase breastfeeding duration among low income women. Health, 4(3). doi:10.4236/health.2012.43022 Retrieved from http://www.scirp.org/journal/health

Hodges, B. C., \& Videto, D. M. (2011). Assessment and planning in health programs (2 ${ }^{\text {nd }}$ ed.). Sudbury, MA: Jones \& Bartlett Learning.

Isom, M.D. (1998). The social learning theory. Retrieved from $\underline{\text { www.crimolology.fsu.edu/crimtheory/bandura.htm }}$

Kingston, D.,Dennis, C., \& Sword, W. (2007). Exploring breast-feeding self-efficacy. Journal of Perinatal and Neonatal Nursing, 21(3), 207-215.

doi:10.1097/01.JPN.0000285810.13527.a7

Kettner, P. M., Moroney, R. M., \& Martin, L. L. (2013). Designing and managing programs: An effectiveness-based approach ( $4^{\text {th }}$ ed.). Thousand Oaks, CA: Sage 
Laureate Education, Inc. (Executive Producer). (2011). Design and evaluation of programs and projects. Baltimore, MD: Author.

Lewallen, L.P., \&Street, D. J. (2010). Initiating and sustaining breastfeeding in African American women. JOGNN 39(6). doi:10.1111/j.1552-6909.2010.01196.x

Magri, E.P.\& Holton-McGuire, L. (2013). Transforming a care delivery model to increase breastfeeding. American Journal of Maternal/Child Nursing 38(3). doi:10.1097.NMC.0b013e3182836af7

Maryland Department of Health and Mental Hygiene (n.d.). Maryland hospital breastfeeding policy recommendations. Retrieved from http://fha.dhmh.maryland.gov/mch/sitepages/hospital-bf-policy.aspx

McCarter-Spaulding, D.\& Gore, R.(2009). Breastfeeding self-efficacy in women of African descent. JOGNN 38(2). doi:10.1111/j.1552-6909.2009.01011.x

McQueen, K.A., Dennis, C.L. Stremler, R.\& Norman, C.D. (2011). A pilot randomized controlled trial of a breastfeeding self-efficacy intervention with primiparous mothers. JOGNN, 40 (1), 35-46. doi: 10.1111/j.1552-6909.2010.01210.x

Pollard, D. \& Guill, M.(2009). The relationship between baseline self-efficacy and breastfeeding duration. Southern Online Journal of Nursing Research, 9(4).

Polit, D. (2010). Statistics and data analysis for nursing research ( $2^{\text {nd }}$ ed.). Upper Saddle River, NJ: Pearson Education Inc.

Rosswurm, M.A. \& Larrabee, J.H. (1999). A model for change to evidence based practice. Image Journal of Nursing Scholarship, 31(4) 317-22.

Sinai Hospital of Baltimore (n.d.) About Siani. Retrieved from http://www.lifebridgehealth.org/Sinai/AboutSinai.aspx 
Sinai Hospital of Baltimore (2013). Community health needs assement report and implementation strategy. Baltimore, Md: Author. Retrieved from http://www.lifebridgehealth.org/uploads/public/documents/community $\% 20$ health/Sinai $\%$ 20Hospital CommunityHealthNeedsAssessmentImplementationStrategy June2013.pdf

Schanler, R.J. (2013). Maternal and economic benefits of breastfeeding. Up to date. Retrieved from http://www.uptodate.com/contents/maternal-and-economic-benefits-ofbreastfeeding

The Associated: Jewish Community Federation of Baltimore. Shalome Baltimore. Retrieved from http://shalombaltimore.org/page.aspx?id=260297

The Joint Commission (2011) Core measure sets: Perinatal care. Retrieved from http://www.jointcommission.org/core measure sets.aspx

United States Breastfeeding Committee (2010). Implementing the joint commission perinatal care core measure on exclusive breast milk feeding. Washington, DC: Author. Retrieved from http://www.usbreastfeeding.org/Portals/0/Coalitions/2010-NCSBC/BTT-Handouts/BTT-29Handout.pdf

Wheeler, B.J. and Dennis, C-L.(2013). Psychometric testing of the modified breastfeeding selfefficacy scale (short form) among mothers of ill or preterm infants. JOGNN, 42(1). doi:10.1111/j.1552.6909.2012.01431.x

White, K.M. and Dudley-Brown, S. (2012). Translaton of evidence into nursing and health care practice. New York, NY: Springer Publishing.

Vermont Oxford (n.d.) Vermont oxford data base. Retrieved from http://www.vtoxford.org/about/about.aspx 
Weimer, J. (2001). The economic benefits of breastfeeding. Food Assistance and Nutrition Research Report (20). Retrieved from http://www.ers.usda.gov/publications/fanrr-foodassistance-nutrition-research-program/fanrr13.aspx

World Health Organization (2011) Exclusive breastfeeding for six months best for babies everywhere. Retrieved from http://www.who.int/mediacentre/news/statements/2011/breastfeeding_20110115/en/index $\underline{\text { html }}$ 
Appendix A: Maryland Breastfeeding Recommendations

\author{
Summary of Maryland Hospital \\ Breastfeeding Policy Recommendations
}

The "Best Practices" hospitals will:

1. Have a written breastfeeding policy that is routinely communicated to all hospital staff.

2. Train all hospital staff in the skills necessary to implement this policy

3. Inform all pregnant women about the benefits and management of breastfeeding

4. Help breastfeeding mothers initiate breastfeeding within 1 hour of birth

5. Encourage breastfeeding on demand

6. Show breastfeeding mothers how to breastfeed and how to maintain lactation even if they are separated from their mothers

7. Practice "rooming in"-encourage breastfeeding mothers and infants to remain together 24 hours a day

8. Give breastfed infants no food or drink, other than breast milk, unless medically indicated.

9. Give no pacifiers or artificial nipples to breastfeeding infants in the hospital, unless medically indicated.

10. Foster the establishment of breastfeeding support groups and refer breastfeeding mothers to them on discharge from the hospital or clinic.

MD DHMH, 2012 


\section{Appendix B: Objectives for RN Educational Intervention}

By the end of the educational module the attendee will be able to:

1. Provide consistent, standardized information related to bedside lactation support

2. Increase personal knowledge related to maternal confidence in successful breastfeeding

3. Understand the benefits of breastfeeding, the physiology of lactation and how to identify women in need of expert lactation consults

4. Improve skills in assessing latch and effective breastfeeding

5. Be familiar with data collection and reports related to the initiation and exclusivity of breast milk feeding

6. Discuss "scripting" to mothers related to breastfeeding

7. Demonstrate accurate EMR documentation related to breastfeeding 


\section{Appendix C: RN Breastfeeding (Educational Intervention) Competency}

\begin{tabular}{|c|c|}
\hline Breastfeeding Competency Checklist & $\begin{array}{l}\text { Name } \\
\text { Date }\end{array}$ \\
\hline $\begin{array}{l}\text { GOAL: Standardize breastfeeding support by OB staff } \\
\text { Nurses }\end{array}$ & $\begin{array}{l}\text { Objectives Met } \\
\text { Yes/No }\end{array}$ \\
\hline $\begin{array}{l}\text { 1. Introduces self and provides adequate explanation } \\
\text { for nursing intervention. i.e. initiation of } \\
\text { breastfeeding, positioning, troubleshooting problems. } \\
\text { (Performance Accomplishment) }\end{array}$ & Yes $\quad$ No \\
\hline $\begin{array}{l}\text { 2. Instructs mother in awaking infant. i.e. talking, } \\
\text { stroking, etc... (Performance Accomplishment) }\end{array}$ & Yes \\
\hline $\begin{array}{l}\text { 3. Assist mother with putting the baby skin to skin. } \\
\text { ( Performance Accomplishment) }\end{array}$ & Yes \\
\hline $\begin{array}{l}\text { 4. Assist the mother to assume positive breastfeeding } \\
\text { positions: a. Cradle b. Football c. Side lying d. Cross } \\
\text { Cradle ( Performance Accomplishment) }\end{array}$ & Yes \\
\hline $\begin{array}{l}\text { 5. Provide adequate explanation of how to support the } \\
\text { breast and infant's head during breastfeeding. } \\
\text { ( Performance Accomplishment) }\end{array}$ & Yes \\
\hline $\begin{array}{l}\text { 6. Applies adequate techniques to promote "Latch" in } \\
\text { the infant and comfort in mother. } \\
\text { ( Performance Accomplishment) }\end{array}$ & Yes \\
\hline $\begin{array}{l}\text { 7. Instructs mother in adequate signs of infant } \\
\text { nutrition. ( Performance Accomplishment) }\end{array}$ & Yes \\
\hline $\begin{array}{l}\text { 8. Feedback on performance : encourage and praise } \\
\text { (Verbal Persuasion) }\end{array}$ & Yes \\
\hline $\begin{array}{l}\text { 9. Give information on impact of } \\
\text { pain/fatigue/anxiety/stress : Medicate as needed } \\
\text { (Physiological and Emotional Status) }\end{array}$ & Yes \\
\hline $\begin{array}{l}\text { 10. Instructs mother in completion of Breastfeeding } \\
\text { Record. ( Performance Accomplishment) }\end{array}$ & Yes \\
\hline $\begin{array}{l}\text { 11. Describes the composition of colostrum. } \\
\text { ( Performance Accomplishment) }\end{array}$ & Yes \\
\hline $\begin{array}{l}\text { 12. Describes adequate timing of breastfeeding. } \\
\text { ( Performance Accomplishment) }\end{array}$ & Yes \\
\hline $\begin{array}{l}\text { 13. Answers questions and/or seeks assistance from } \\
\text { LC. }\end{array}$ & Yes \\
\hline $\begin{array}{l}\text { 14. Demonstrate adequate EMR documentation of } \\
\text { breastfeeding support. }\end{array}$ & Yes \\
\hline \multirow[t]{2}{*}{$\begin{array}{l}\text { 15. Discussion and information on previous } \\
\text { breastfeeding experience: provide information } \\
\text { (books/video) (Vicarious Experience) }\end{array}$} & Yes \\
\hline & $\begin{array}{l}\text { Date completed } \\
\text { Validated By: }\end{array}$ \\
\hline
\end{tabular}




\section{Appendix D: RN Documentation of Breastfeeding Interventions}

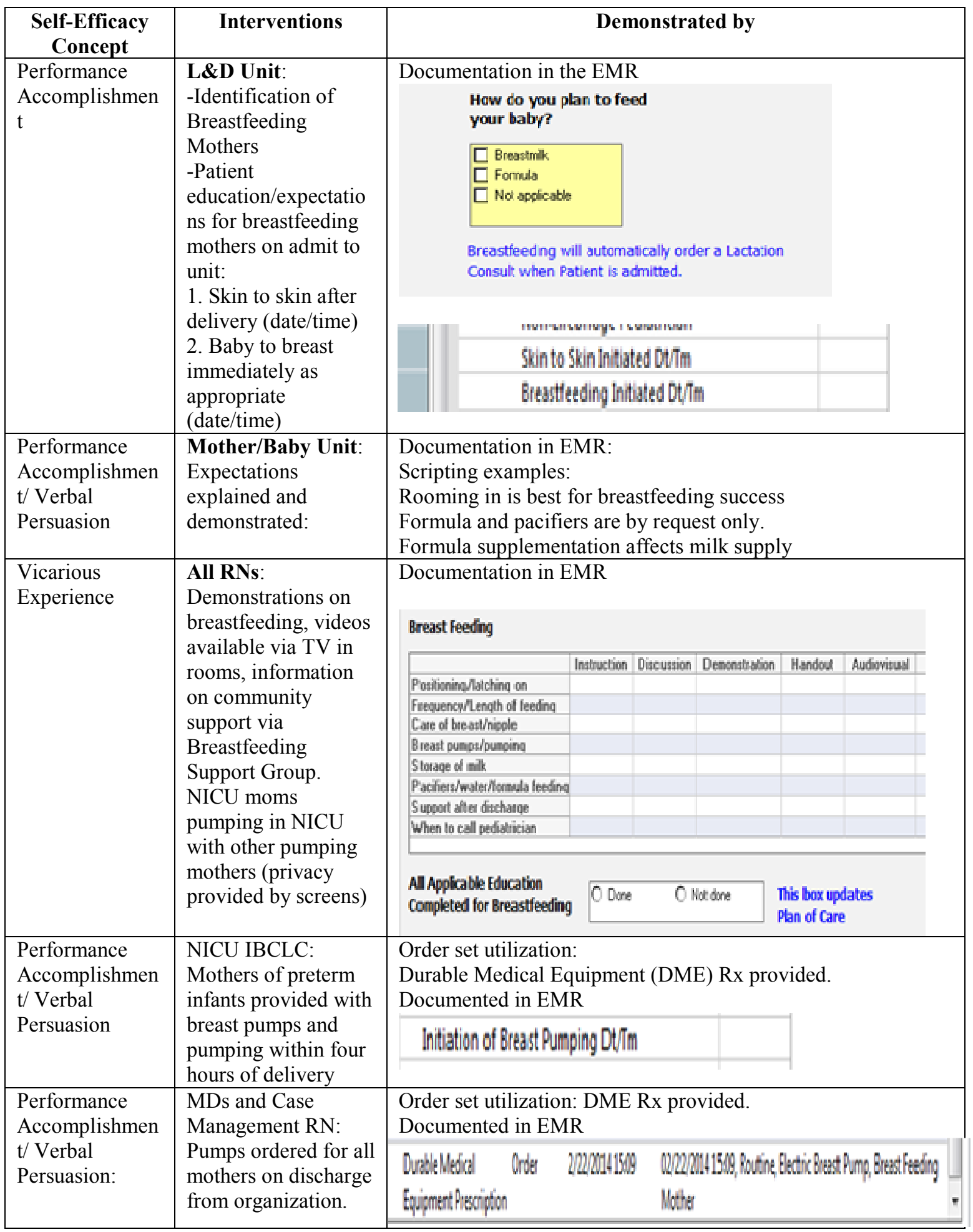


Appendix E: The Essentials of Doctoral Education for Advanced Nursing Practice

I. Scientific Underpinnings for Practice

II. Organizational and Systems Leadership for Quality Improvement and Systems Thinking

III. Clinical Scholarship and Analytical Methods for Evidence-Based Practice

IV. Information Systems/Technology and Patient Care Technology for the Improvement and Transformation of Health Care

V. Health Care Policy for Advocacy in Health Care

VI. Interprofessional Collaboration for Improving Patient and Population Health Outcomes

VII. Clinical Prevention and Population Health for Improving the Nation's Health

VIII. Advanced Nursing Practice

American Association of Colleges of Nursing (2006) 
Appendix F: Presentation to the Women \& Children's Leadership

\section{INCREASING INITIATION AND EXCLUSIVITY OF BREASTFEEDINC IN THE HOSPITALIZED POSTPARTUM DYAD}

A PVIEBP project presentation to Women 8 Chidiren's Lexdership Team

Candace L Rouse, RNC, MSN, CNS-BC oB Clinical Nurse Specialist

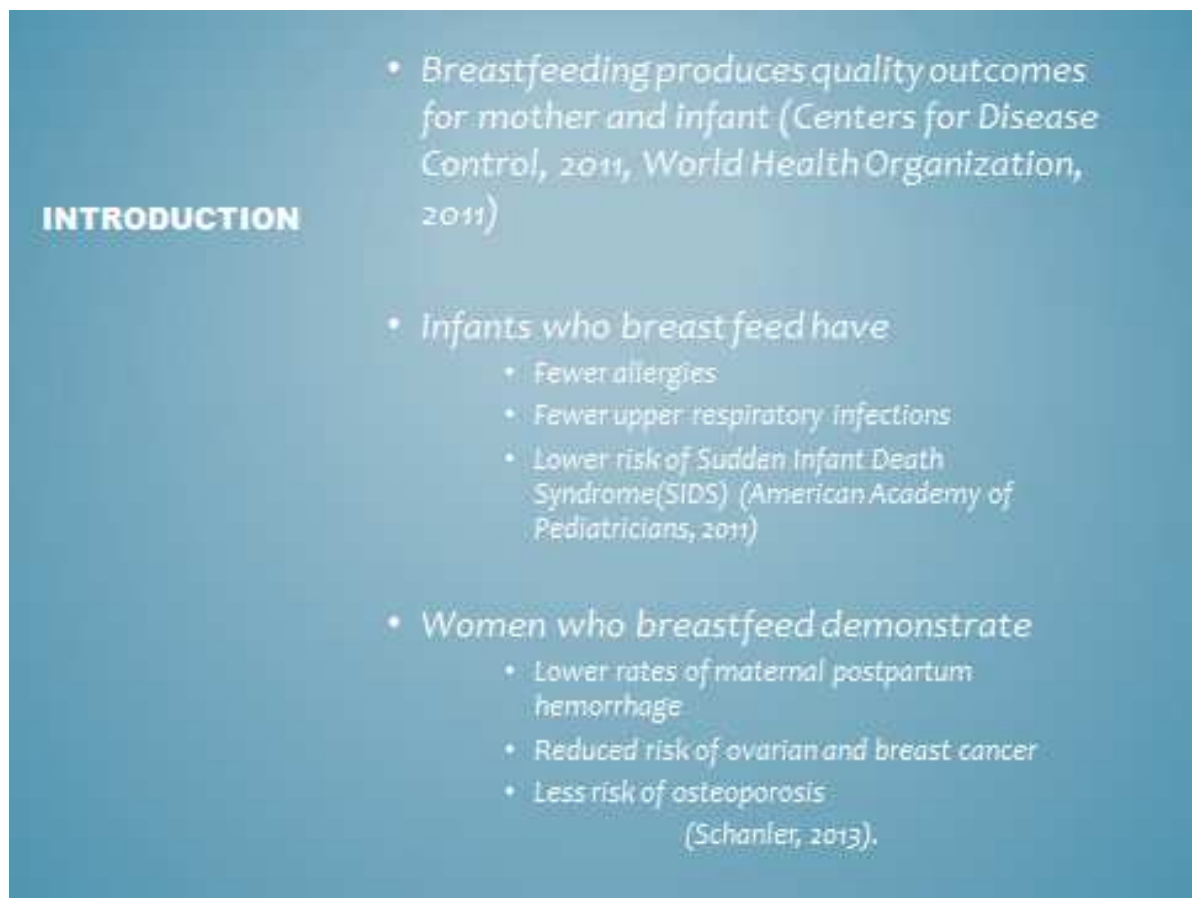


- USA: current

\section{MACRO}

ASSESSMENT OF

NEED FOR CHANGE
- Breastfeeding initiation $=75 \%$

- Exclusivebreastfeedingat discharge $=75 \cdot 4 \%($ CDC, 2012)

- Healthy People 20zo target breastfeeding goals:

- Inithrion = 8.,98

- Breustfeeding exclisively during birth hospitalization $=85,8 \mathrm{E}$

- 2014 Perinatal Core Measures (the Joint Commission, 2011)

- Mandatory reporting exclusive breastfeeding while hospitalized

- Benchmaris being set from reported data
ASSESSMENT OF

NEED FOR

CHANGE:

STATEAND

LOCAL LEVEL.
- Maryland breastfeedingrates:

- Ever breastfed =72.6\%

- Exclusive breastfeedingat discharge $=77 \cdot 3$ \& $(C D C, 2012)$

- Project hospital data (FY13Q1):

- Initiation $=55 \cdot 4 \%$

- Exclusive breastfeeding at discharge $=63.2 \%$

(Sinai Hospital, 2013) 


\section{BENCHMARKED TARGETS FOR INSTITUTION}

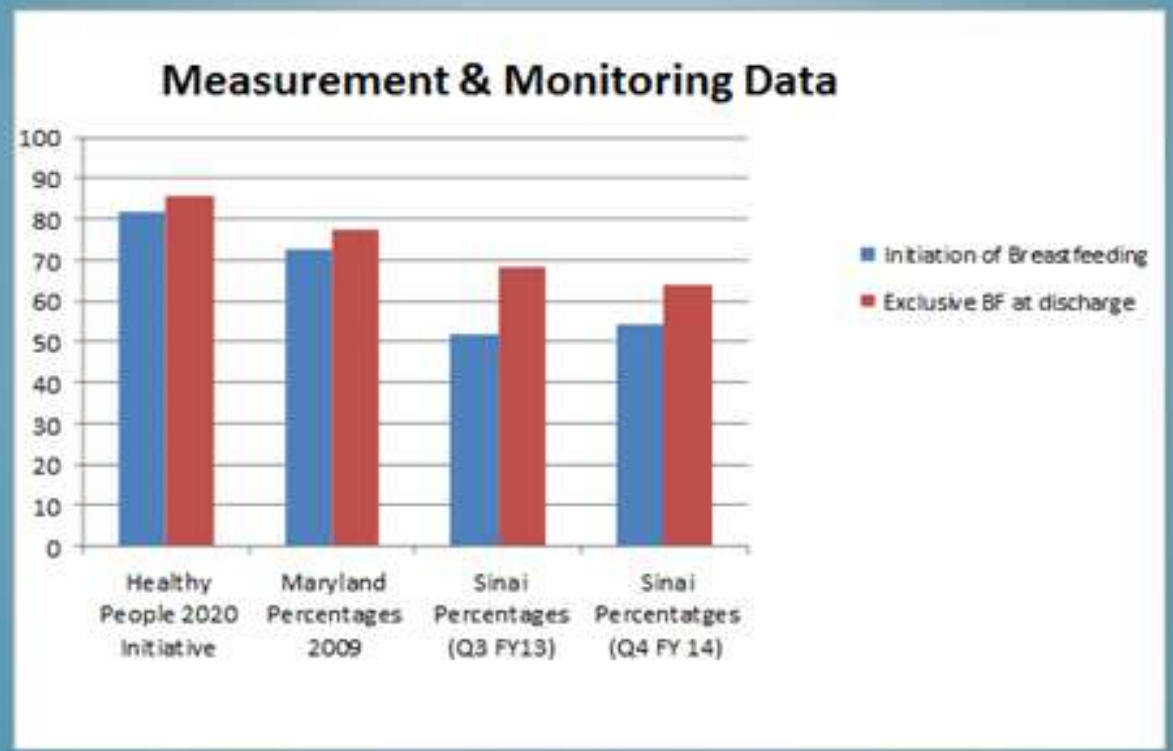

PROJECT PROPOSAL OBJECTIVES

\section{Objective}

Demonstrate increased initiation of breastfeeding immediately after birth

Demonstrate an increase in exclusive breastfeeding during the newborn's entire hospital stay

\section{Measurable Outcome}

Number and percentage of mother's who were able to initiate breastfeeding within one hour of birth (CDC, 2010)

Number and percentage of non-NICU term babies exclusively breastfed during hospital stay (Perinatal Core Measure, The Joint Commission, 2011) 

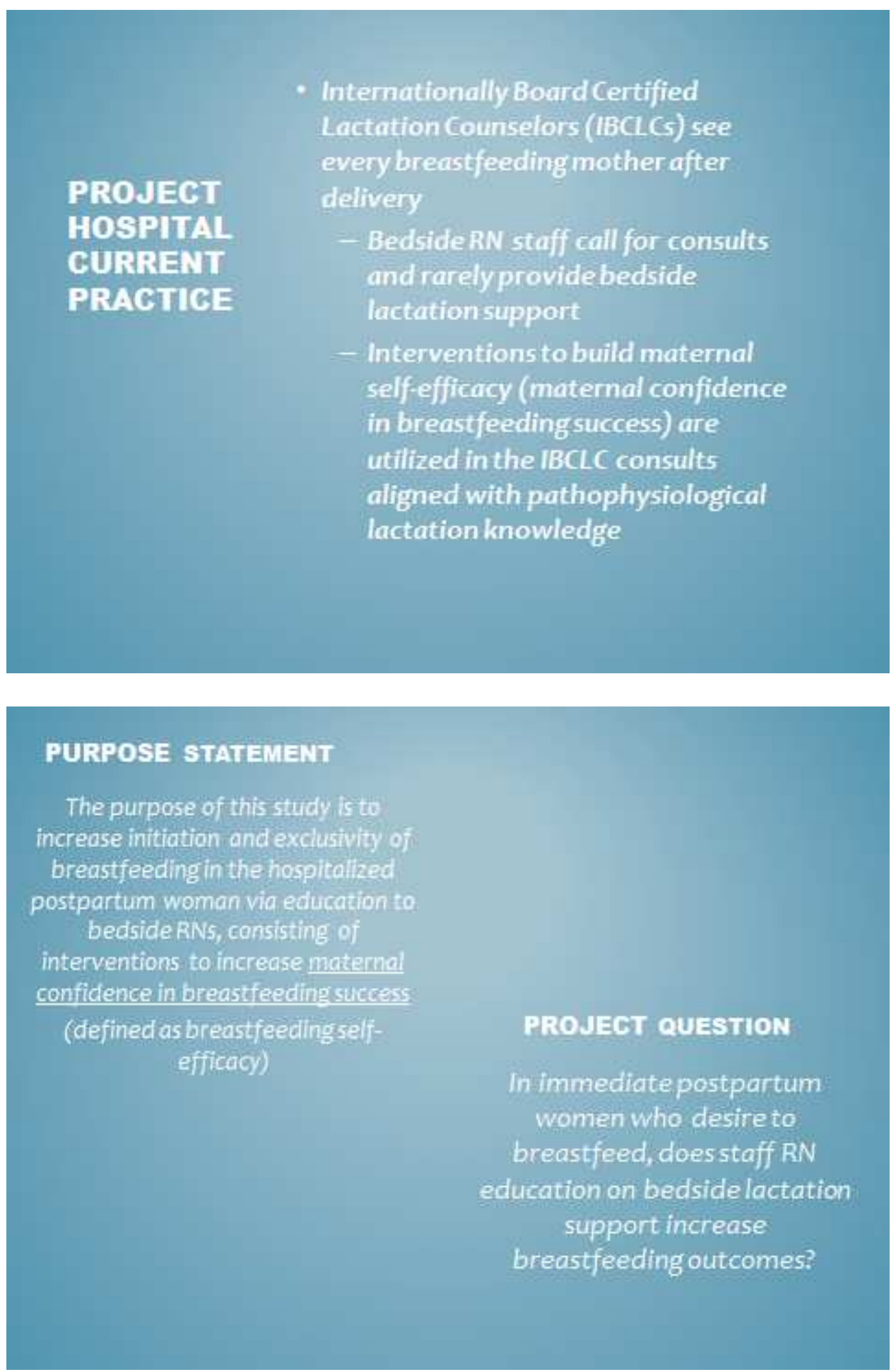


\section{REVIEW AND GRADING OF LITERATURE}

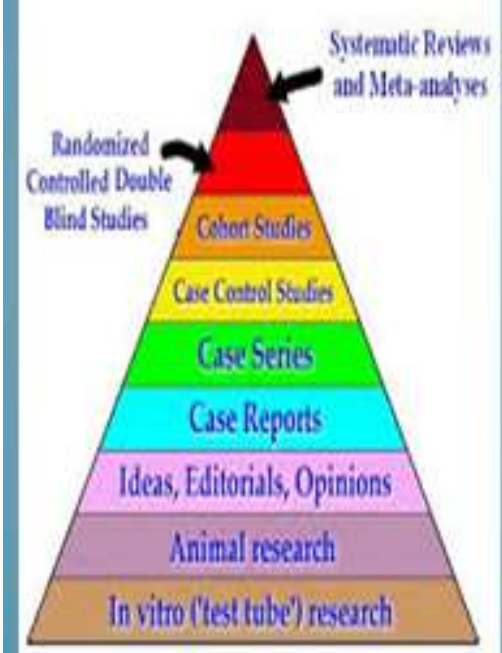

- Meturanalysicy

- Rindom Control Trialit

- Quas Experimantalit

- Bescriptiver1

- Correlational :s

- Cohortis 1

- Compotativer 1

- Case Reports 4

\section{Conctusions:}

* Maternal confidence is a strong predictor for initiating and maintaining breastfeeding:

* RiN stafflactation support increased breastfeedingrates

\section{DEFINITIONS}

- Exclusive hreastfeeding at dischargefrom hospital

= No formula supplementation while nessbom is in hospital

- Selferficecy

- Anindividuaits bellef thut they will occomplisha goals an expectation that a positive outcome will occur as a resulte of their mastery of a situation or a skill (Bandura, 1977 os ated by Dennisi 1999).

- Breastfeedingselfsefficacy

- Mother's perception of herability or confidence to breaste eed her infont it affects her decisions regarding beginning and continuing br east feeding (Pollard, 2009), it also affects how she will react to any cultural orphysical barriers to breastfeeding.

- Concepts

- Mastery of pest experiences

- 5ocial modeling by obserwation of others

- Social persuasion by encouragenent from others

$\therefore$ Leurning how to deal with poin, anniety and fatigue to effect. stickess 


\section{THE BREAST-FEEDING SELF EFFICACY MODEL}

\section{Social Persuasion} Confidence Building

Performance Mastery:

Breastfeeding immediately after birth Multiple breastfeeding experiences

vicarious Experience
Positive Reinforcement

Control negative states

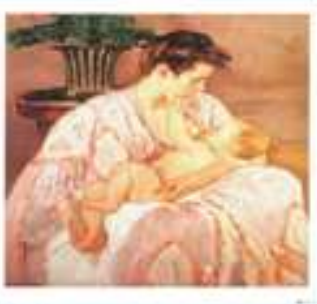

Self Efficacy Judgments: BehavioriPerformance
Anticipatory Cuidance

Normalize anxiety, pain, fatigue with strategies

Physiological \&

Emotionalstates

Dennis, C.L.(1999)

\section{Maternal breastifeeding self-efficacy will} be measured as an outcome in this study by the institution's subsequent increase in

$$
\text { breastfeeding data }
$$

(initiation within one hour of delivery and exclusive breastfeeding during hospitalization) 


\section{EVIDENGE \\ BASED \\ PRACTICE \\ GHANGE \\ DESIGN}

- Education and involvement of the Lactation Operations Group (LOO)

- Education and involvement of bedside RN staff (L\&D, Postpartum/Newborn Nursery [MB]) by the LOG

- Education Module Content

- Breastfeeding self efficacy concepts

- Lactation Support concepts: Skin to skin, Little or no separation after birth as appropriate, Nosupplementation

- EMR doctumentation

- Competency Checklist completion

- Audits of EMR documentation

EDUCATIONAL MODULE TO

THE BEDSIDE RNS:

OBJECTIVES

- Provide consistent, standardized information related to bedside lactationsupport

- Increase personal knowledge related to maternal confidence in successful breast feeding

- Understand the benefits of breastfeeding, the physiology of lactation and how to identify women in need of expert lactation consults

- Improve skills in assessinglatch and effective breastfeeding

- Be familiar with data collection and reports related to the initiationand exclusivity of breast milk feeding

- Discuss "scripting" to mothers related to breastfeeding

- Demonstrateaccurate EMR documentation related to breastfeeding 


\section{Breastfeeding Competency Checklist Components}

\section{COALS Standardize breastfeeding support by OB staff Nurses}

4. Introduces se f and peovides adequate explanation for nursing interventions les initation of

breastfeeding, positioning, troubleshooting probiems.

(Performance Accomplishment)

$z$ Instructs mother in awaking infant, ie, taking, stroking, etci., (Perfomance Accomplishment)

3. Assist mother with putting the baby skin to skin. (Perfomance Accoomplishment)

4. Assist the mother to assume positive breastfeeding positionsi a Cradle by football C. Side hing di Cross

Crade (Rerfommance Accomplishment)

5. Provide adequate explanstion of how to support the breast and infant's head during breastfeeding.

(Performance Accomplishment)

6. Applies adequate techniques to promote "Latch" in the infant and comfort in mother,

(Performance Accomplishment)

7. Instructs mother in adequate signs of infant nutrition. (Perfomance Accomplishment)

8. Feedbock on perfomance :encourage and praise (Verbai Persuasion)

9. Cive infonmation on impact of painlfatiguelanxietylstress: : Medicate as needed (Physiological and Emotional Status?

10. Instructs mother in completion of Breastfeeding Record. (Perfomance Accomplishment)

4h. Describes the composition of colostrum.

(Performance Accomplishment)

12. Describes adequate timing of breastfeeding. (Performance Accomplishment)

13. Answers questions andior seeks assistance from LC.

14. Demonstrate adequate EMR dotumentation of breastfeeding support.

15. Discussion and information on previous breastfeeding experiencei pcovide information (books/video)

(Vicarious Experience)

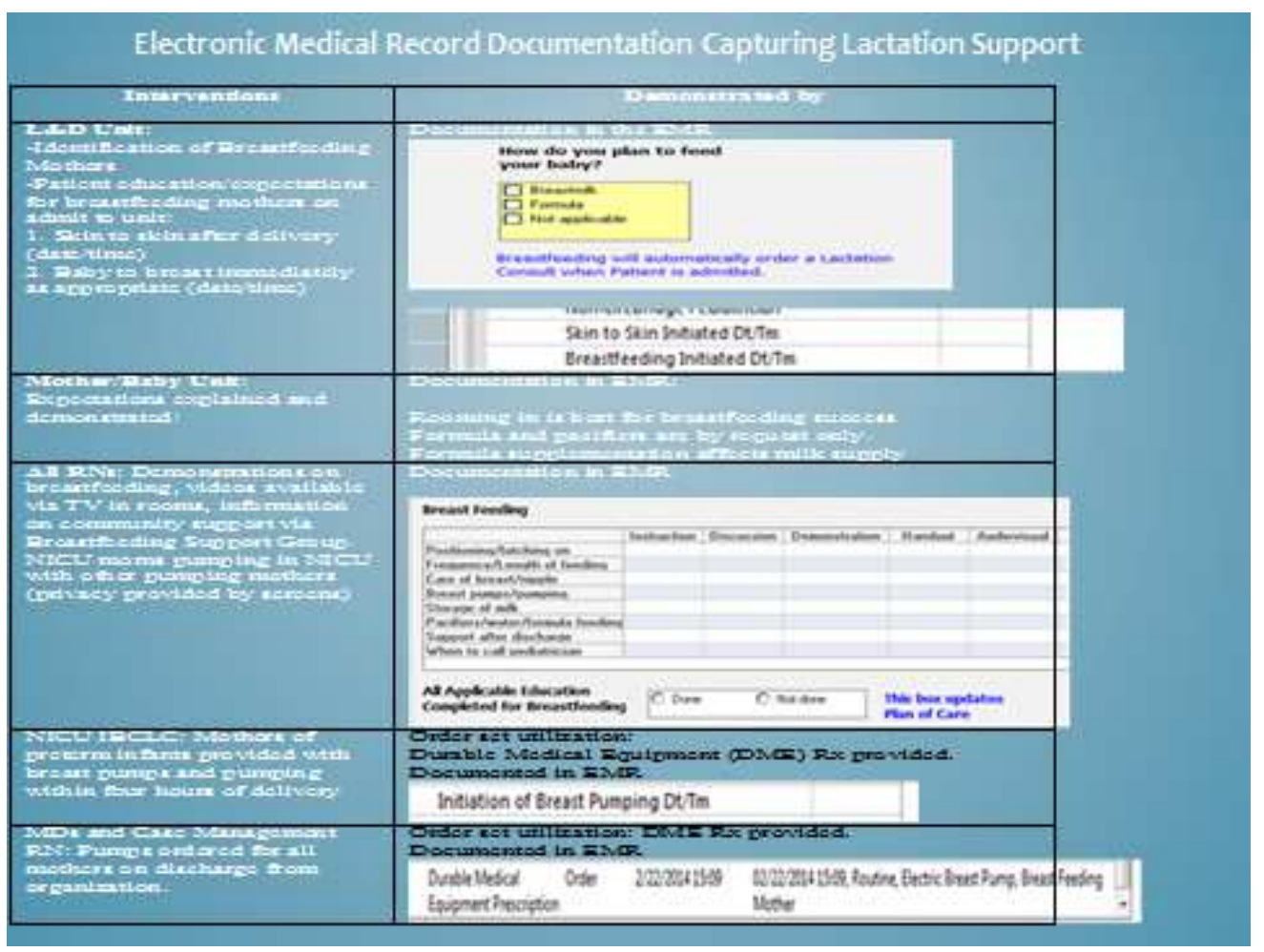


- 467 acute beds, 35 newborn bassinets and 18 Neonatal intensive Care beds, 2200 deliveries/year

POPULATION \& SAMPLING

- Teaching institutions160BGyn, 12 Peds residents

- Level ilinicu

- Perinatal Referral Centers high risk Maternal Fetal Medicine clinic located adjacent to the Perinatal (LED, Mother/Baby, and NICU) Service Units

- Proposal target population = hospitalized immediate postpartum women in a coastal mid-Atlantic inner city hospital who desire to breastfeed.

- Exclusiondata

- Multiplegestation

- NICU admits

\section{SUSTAINABILITY}

- LeG involvaments Shared goals and Ownership of change

- Aware of need forthinge from dota reports and literature review

- Tronslated evidence into proctice change

- Linfied nursing care fo patient outcomes

- Incravied bedsinte lactatian support =increased bravatfecaling

- Participated in education of stoff to disseminate the ahange

- Practice change will become part of the Unit culture

- Lactation Education to all new RN staff in all perinatal units.

- Audits of EMR documentation provide information on progress and help to hardwire change

- Aigns with mission statement of organization:

- "to improve the community one (two) person(s) at a time"t (Sinai Hospital of Baltimore, zar1) 


\section{REFERENCES}

American Araderny of Pedilatries (zon). Brenstfeeding and the use of human milk. Pediatrics, 22 (3). Doin 16.154a/peds.2011-3552)

Centers for Disease Control and Prevention (2011). Breostjeeding report card. Retriaved from

http:llwwwadcgovibreastfeeding/pdf/2012BreastfeedingheportCard.

Dennis, G.L (1999). Theoretival underpinnings of breastefeding confidencet A self efficacy fromework Joumal of Human Lactation, is $(3)$. dotito. $1177 / 089033449901500303$.

Kettner, P. M. Moroney, R. M, \& Martin, L. L (2013), Designing and manoging programss An Gffectiveness-bosed opproach ( $4^{\text {th }}$ ed.). Thousand eaks, CA: Sage

Maryland Department of Heaith and Mental Hygiene (n.d.) Maryland hospital breastfeeding policy recommendations. Retrieved from

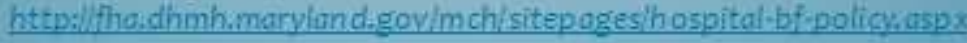

Maqueen, K.A., Dennis, CL. Stremler, R. and Norman, C.D. (20n1). A pilot randomized controlied trial of a breastfeeding seif efficacy

intervention With primiparous mothers: JOGNN, $40(\mathrm{\theta}), 3546$. Doit

$10.111 / j .1552-6909.2010 .01210 . x$

\section{REFERENCES}

Rosswurm, M.A. \& Larrabec, J.H. (1999). A model far change to evidence bused prostice. Imoge journal of Nursing Scholarship, 31(4) 317-22.

Sinai Hospital of Baltimore (nd.) About Siani. Retrieved from http://wwwlifebridgehealth.org/Sinai/About5ingi.aspx

Sinai Hospital of Baitumore (2013). Community heal th needs nssement report and implementotion strutegy, Baltimors, Md: Author. Retrieved from htto:l/www.lifebridgehealth.org/uploadsipubliddocuments/communityzzahe aith/SinaikzoHospital CommunityHeoithNeedsAssessmentimplementntion 5tr ategy Junezorj.pdf

Schanler, R.j. (2013). Maternal and economic benefits of breastfeeding. Up to date. Retrieved from http:iliwwwuptodate.com/contentsimaternal: and-economic-benefits-of-breastfeeding

The Associated: Jewish Community Federation of Baltimorte. Shalome Baltimore. Retrieved from http:lishalombaltimore.org/poge.asp ?id $=260297$

The Joint Commission (20t1) Core measure sets: Perinatai care. Retrieved from httpil wwwilointcommissian.orgicore, measure_setsiospx 
REFERENCES

Wheeler, B.:. and Dennis, CL. (2015). Psychometric testing of the modiffed breastfeading self efficacy scale (short form) among mothers of ill or preterm infants. JOCNN, $42(1)$. Doin10.111//2552.6909.2012.01431.x

Vermont oxford (nd.) Vermont oxford dato bale. Retrieved from http:l www.vtoxford,orglaboutlabout.asp.

World health Organization (2011) Exclusive breostifeeding for six months best for babies everywhere. Retriaved from http:llwww, who.intimediacentreinaws/statementsizomibreastfeedi nezorrons/en/index.ht $\mathrm{ml}$ 
Appendix G: Evidence-Based Practice Poster Abstract Submission Form

\author{
MERCY MEDICAL CENTER \\ DIVISION OF NURSING EBP / RESEARCH 3rd SYMPOSIUM \\ “Navigating the Course: Redefining the Nurses' Role in Today's Healthcare \\ Environment"
}

\title{
EVIDENCE-BASED PRACTICE POSTER ABSTRACT SUBMISSION FORM
}

Abstract text including subheadings is limited to 400 words. Use Calibri 12 pt font and single space text. References should be submitted on a separate page in APA format

Title: Increasing Initiation and Exclusivity of Breastfeeding in the Hospitalized Postpartum Dyad

Authors (First Name, Last Name and Credentials):

Candace L Rouse, RNC, MSN, CNS-BC

Institutional Affiliation(s):

Sinai Hospital of Baltimore, Md.

\section{OUTLINE}

- Introduction

Quality outcomes from exclusive breastfeeding for mother and infants have been investigated nationally and internationally (Centers for Disease Control, 2011, World Health Organization, 2011). Numerous projects are ongoing in institutions to encourage women to breastfeed and consequently discourage formula supplementation (Baby-Friendly USA, 2013). This project describes a successful intervention to encourage increased initiation and exclusivity of breastfeeding in the immediate postpartum period for the maternal infant dyad.

\section{- Practice Question}

In immediate postpartum women who desire to breastfeed, does staff RN education on bedside lactation support increase breastfeeding outcomes?

\section{- Summary of Evidence}

Twelve articles were critically analyzed, 1 meta-analysis, 1 random control trial, 1 quasi experimental, 1 descriptive, 2 correlational, 1 cohort, 1 comparative and 4 case reports for this project. Conclusions were that

1. Maternal confidence is a strong predictor for initiating and maintaining breastfeeding and that

2. RN staff lactation support increased breastfeeding rates 


\section{- Outcomes}

The outcome measures demonstrated an increase in scores for breastfeeding. The initiation of breastfeeding within the first hour of life score rose from $55.4 \%$ to $62.3 \%$, with the exclusivity of breast milk feeding while in the hospital rose from $63.1 \%$ to $70.78 \%$.

\section{- Translation to Practice}

The staff RNs became more engaged in lactation support and felt more comfortable with a standardized breastfeeding advice and care model. The lactation support now starts on admission with the L\&D RNs who begin the conversation about breastfeeding, explaining immediate skin to skin and initiation of breastfeeding within the first hour. The Postpartum/Nursery RNs are continuing the lactation support by attempting to keep the mother and baby together via the "rooming in" model and with standardized "scripted" advice re: formula reducing milk supply, etc.

\section{- Conclusion}

Success was dependent upon an EBP model (Rosswurm \& Larrabee, 1999) as a framework. Translation of research to the bedside incorporated specific interventions noted in studies based on Dennis's Theory of Breastfeeding Self Efficacy (1999), which was grounded in Bandura's social cognitive theory of self- efficacy (1977, as cited by McQueen et al., 2011). Maintaining success of this project will be demonstrated by sustaining the engagement of the bedside $\mathrm{RN}$ in lactation support and ongoing EBP. 